\title{
Cyanoethylation of the glucans dextran and pullulan: Substitution pattern and formation of nanostructures and entrapment of magnetic nanoparticles
}

\author{
Kathrin Fiege ${ }^{1}$, Heinrich Lünsdorf ${ }^{2}$, Sevil Atarijabarzadeh ${ }^{3}$ \\ and Petra Mischnick ${ }^{* 1,3}$
}

\section{Full Research Paper}

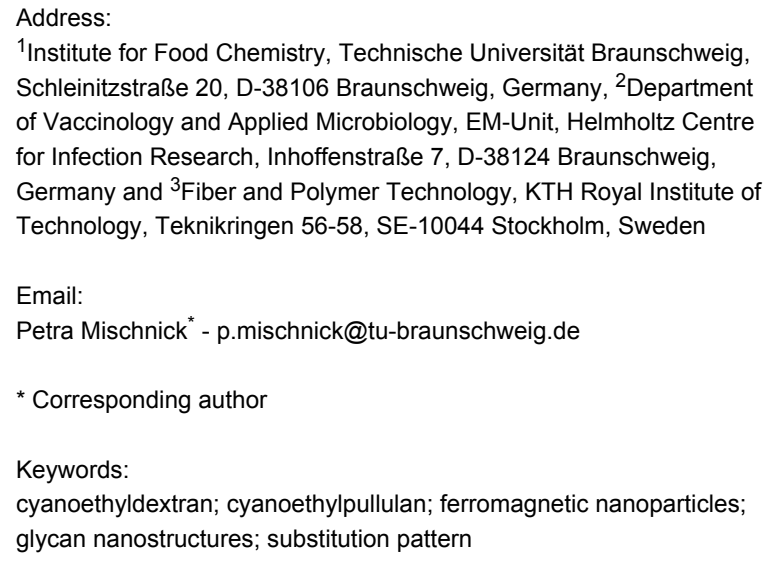

${ }^{1}$ Institute for Food Chemistry, Technische Universität Braunschweig, Schleinitzstraße 20, D-38106 Braunschweig, Germany, ${ }^{2}$ Department of Vaccinology and Applied Microbiology, EM-Unit, Helmholtz Centre for Infection Research, Inhoffenstraße 7, D-38124 Braunschweig, Germany and ${ }^{3}$ Fiber and Polymer Technology, KTH Royal Institute of Technology, Teknikringen 56-58, SE-10044 Stockholm, Sweden

Email:

Petra Mischnick ${ }^{*}$ - p.mischnick@tu-braunschweig.de

* Corresponding author

Keywords:

cyanoethyldextran; cyanoethylpullulan; ferromagnetic nanoparticles; glycan nanostructures; substitution pattern

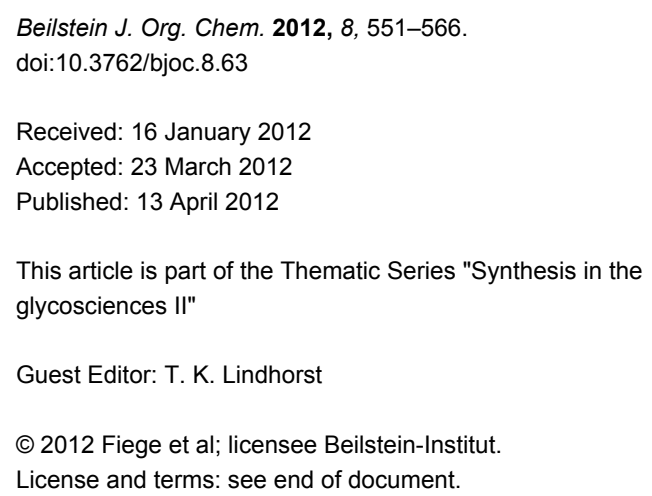

\begin{abstract}
Cyanoethylglucans with a degree of substitution in the range of 0.74 to 2.40 for dextran and 0.84 to 2.42 for pullulan were obtained by Michael addition of acrylonitrile to the glucans under various conditions. Products were thoroughly characterized, comprising elementary analysis, NMR and ATR-IR spectroscopy, and analysis of the substituent distribution in the glucosyl units by GC-FID and GC-MS of the constituting monosaccharide derivatives. Nanostructuring of the highly substituted cyanoethylpolysaccharides was performed by dialysis against a non-solvent. In the presence of ferromagnetic iron-oxide nanoparticles, multicore cyanoethylglucan-coated ferromagnetic nanoparticles were formed by selective entrapment. The specific interaction between cyano groups and iron could be proven. The size distribution and morphology of the nanoparticles were analyzed by dynamic light scattering (DLS), scanning electron microscopy (SEM) and energy-filtered transmission electron microscopy (EF-TEM) with parallel electron energy loss spectroscopy (PEELS).
\end{abstract}

\section{Introduction}

Cyanoethylation has been widely applied to polysaccharides, e.g., to cellulose [1], inulin [2], and starch [3]. Onda reported on cyanoethylation of pullulan with degrees of substitution (DS) up to 2.71 [4]. In contrast to Williamson-type etherifications, the base is not consumed in this nucleophilic addition of acrylonitrile, which is a reversible and thermodynamically controlled 
reaction. While $O$-cyanoalkylglycans are of interest as such, they have also been used as precursors for amino-functionalized polysaccharides [2,5-8].

Introducing a cyanoethyl group offers various potential advantages. First, cyanoethylpolysaccharides show remarkable electric properties: These compounds used as gel electrolytes exhibited an enhanced ionic conductivity up to $2.4 \times 10^{-3} \mathrm{~S} / \mathrm{cm}$. Thus, a lithium ion polymer battery with cyanoethylpullulan as a matrix polymer could be built with high charge/discharge efficiency [9]. Another example is a vertical electrochemical transistor based on poly(3-hexylthiophene), which was realized by making use of the film-forming qualities of cyanoethylpullulan [10].

Partial hydrophobization of polysaccharides by the introduction of nonpolar residues enables nanostructuring by self-assembly of these compounds. Heinze et al. demonstrated that hydrophobic dextran derivatives form spherical particles on the nanometer scale when a solution of the polymer material is dialyzed against the poorer solvent water. A certain degree of hydrophobicity and amphiphilic balance is necessary to form stable particles [11-14]. We also observed nanostructure formation of alkynyldextrans [15]. Embedding magnetic iron cores in the polymer particle allows for control by magnetic fields. Magnetic separation techniques or magnetic particle imaging can be performed. Applications, such as drug delivery or targeting, hyperthermia and biosensing can be realized [16-18]. Binding of stabilizing organic shells to ferric oxide nanoparticles is usually mediated by carboxylate groups [19]. The interaction of magnetic nanoparticles, coated with glucans (cellulose, pullulan and dextran), with human cells was reported by Heinze et al. [17,20].

A prerequisite for any application in pharmaceutical as well as technological fields is the structural characterization of the material. Cyanoethylation is established for polysaccharides, but the substituent pattern has only been studied for cyanoethylamylose and starch [3]. In most cases, the products have only been roughly characterized by NMR and IR spectroscopy or by elementary analysis [1,2]. Verraest described the substituent distribution in $O$-cyanoethylinulin by HPLC analysis and ${ }^{13} \mathrm{C}$ NMR spectroscopy [7]. The structure and the solution properties of cyanoethylcellulose were investigated by FT-IR and ${ }^{13} \mathrm{C}$ NMR spectroscopy, as well as by light scattering [21,22]. Cellulose and starch derivatives have been studied more extensively due to their frequent use, e.g., market share and bulk flow in industrial processing [23].

Pullulans and dextrans (Figure 1) have not received the attention these fascinating polymers deserve, due to their lower trading volume and higher price. But in recent years their
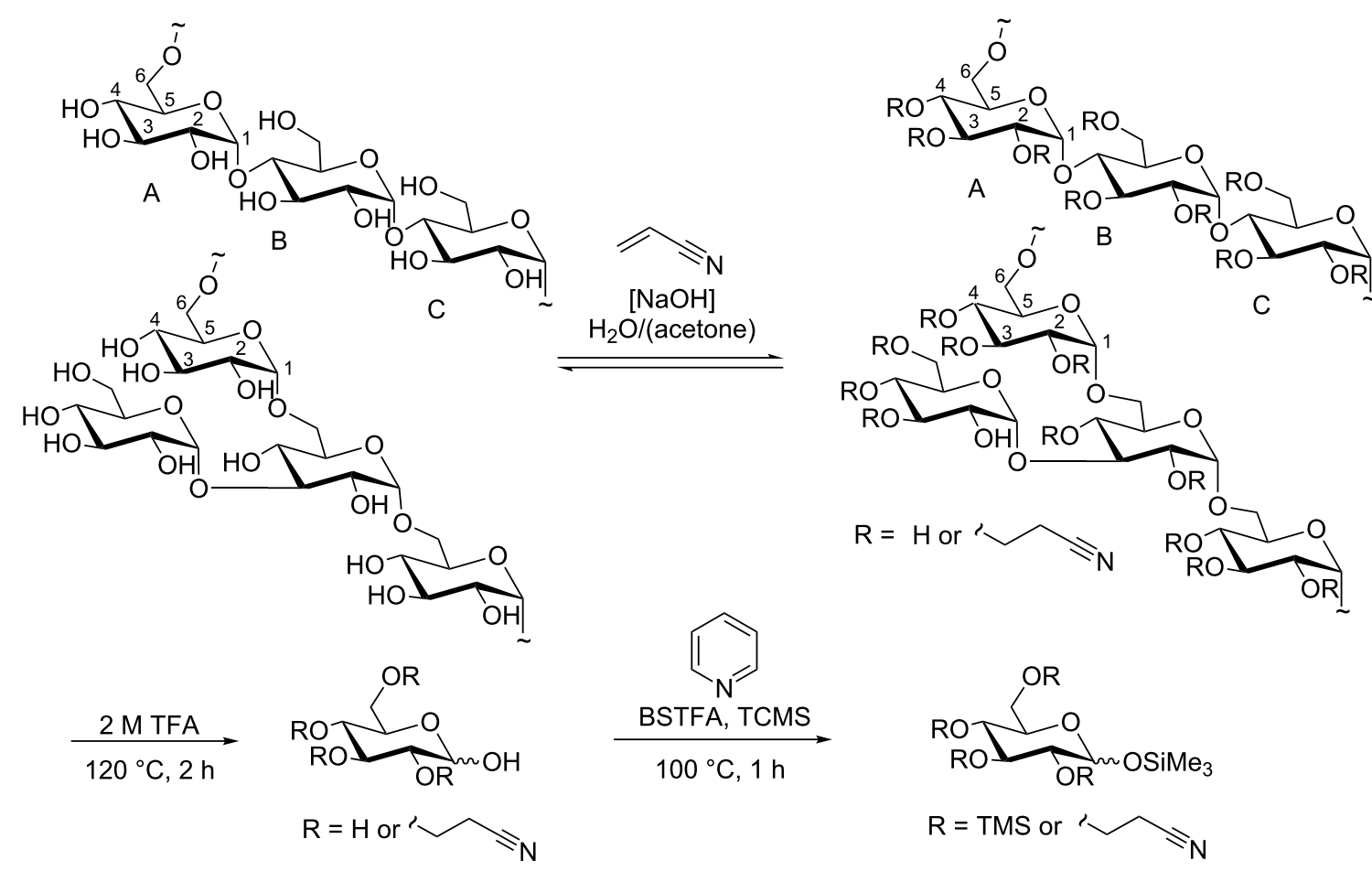

Figure 1: Polysaccharide structures of pullulan and dextran cyanoethylation with acrylonitrile and $\mathrm{NaOH}$ as catalyst; sample preparation for GLC/ GLC-MS analysis: depolymerization and silylation. 
importance for special biochemical or pharmaceutical applications, such drug delivery or biosensor technology, has grown, due to their special properties such as water solubility, low viscosity and film formation [24-27]. Pullulan is a homopolysaccharide of D-glucose secreted by Aureobasidium pullulans. The repeating units of this linear and regular glucan are maltotrioses $($ Glc- $\alpha-1 \rightarrow 4-G l c-\alpha-1 \rightarrow 4-G l c)$, which are $\alpha-1 \rightarrow 6$-linked. Due to this linkage pattern, pullulan is very flexible and dissolves readily in water, with low viscosity. Films can be easily prepared. Pullulan is nontoxic, even edible, biocompatible and biodegradable [28,29]. Several applications in pharmaceutical and food technology have been reported. A summary for biotechnological applications of pullulan is given by Leathers [30].

Dextran is also a microbial glucan, e.g., from Leuconostoc mesenteroides. The main chain is $\alpha-1 \rightarrow 6$-linked and, in contrast to pullulan, randomly branched to various extent at positions O-3, O-4 and/or O-2, beside short stumps consisting of 1 to 2 glucose units; the $1-2 \%$ long-chain branching influences the properties of commercially available dextran [31-33]. Due to their nontoxicity and biocompatibility, dextrans are applied as blood-plasma expander. Dextran derivatives are used in many biomedical and bioanalytical applications [34] and are the subject of further developments in this field [35]. Therefore, we selected pullulan and dextran as candidates for a linear and a branched polysaccharide in our cyanoethylation studies. Cyanoethylglucans of different DS values were produced. Another objective of our approach was the detailed determination of the substitution pattern on the monomer level. Furthermore, nanostructuring of highly substituted cyanoethylglucans with and without ferromagnetic nanoparticles was investigated.

\section{Results and Discussion Synthesis and characterization of cyanoethyl- glucans}

Dextran $(6 \mathrm{kDa})$ and pullulan $(100 \mathrm{kDa})$ were reacted with different amounts of acrylonitrile (AN) and sodium hydroxide in water. According to the patent of Onda [4], acetone was applied as a solubility mediator in some reactions. Reaction conditions were varied to obtain scarcely, moderately and highly substituted cyanoethylglucans. Products were isolated and purified by dialysis. Reaction parameters are shown in Table 1. DS values ranging from 0.74 to 2.40 (dextran, CED1-CED-3) and 0.84 to 2.42 (pullulan, CEP-1-CEP-3) were obtained by GLC analysis. Up to a DS of around 1.50 , the products were still water-soluble. Derivatives with a DS above 2 showed good solubility in acetone, DMSO or DMF. Product

\begin{tabular}{|c|c|c|c|c|c|c|c|c|}
\hline sample & & & CED-1 & CED-2 & CED-3 & CEP-1 & CEP-2 & CEP-3 \\
\hline reaction & mass educt & [g] & 1.20 & 1.20 & 0.50 & 1.20 & 1.20 & 0.50 \\
\hline \multirow[t]{9}{*}{ conditions } & & [mmol/glc] & 7.4 & 7.4 & 3.1 & 7.4 & 7.4 & 3.1 \\
\hline & $\mathrm{H}_{2} \mathrm{O}$ & {$[\mathrm{mL}]$} & 4 & 4 & 5 & 4 & 4 & 5 \\
\hline & acetone & {$[\mathrm{mL}]$} & - & 1 & 4.75 & - & 1 & 4.75 \\
\hline & $\mathrm{NaOH}$ & [equiv/glc] & 0.2 & 0.2 & 2 & 0.2 & 0.2 & 2 \\
\hline & AN & {$[\mathrm{mL}]$} & 1.9 & 1.9 & 4.65 & 1.9 & 1.9 & 4.65 \\
\hline & & [equiv/glc] & 4 & 4 & 23 & 4 & 4 & 23 \\
\hline & time & {$[\mathrm{h}]$} & 0.5 & 0.5 & 24 & 0.5 & 0.5 & 24 \\
\hline & temperature & {$\left[{ }^{\circ} \mathrm{C}\right]$} & 45 & 45 & 20 & 45 & 45 & 20 \\
\hline & mass product & {$[\mathrm{g}]$} & 1.23 & 1.30 & 0.77 & 1.17 & 1.29 & 0.71 \\
\hline \multirow[t]{7}{*}{ DS } & $\mathrm{DS}_{\mathrm{EA}(\mathrm{N})^{\mathrm{a}}}$ & & 0.86 & 1.46 & 2.68 & 0.90 & 1.35 & 2.32 \\
\hline & $\mathrm{DS}_{\mathrm{EA}(\mathrm{CN})^{\mathrm{b}}}$ & & 0.91 & 1.55 & 2.72 & 0.97 & 1.42 & 2.32 \\
\hline & $\mathrm{DS}_{\mathrm{NMR}(1)^{\mathrm{C}}}$ & & 1.01 & 1.81 & 2.37 & - & - & - \\
\hline & part. $\mathrm{DS}_{\mathrm{NMR}(2)}$ at $\mathrm{O}-2^{\mathrm{d}}$ & & $0.47(46.1)$ & $0.72(39.6)$ & - & - & - & - \\
\hline & $\mathrm{DS}_{\mathrm{NMR}(3)}^{\mathrm{e}}$ & & 0.97 & 1.61 & 2.51 & 0.89 & 1.31 & 2.43 \\
\hline & $D S_{G C}^{f}$ & & 0.74 & 1.39 & 2.40 & 0.84 & 1.52 & 2.42 \\
\hline & $\mathrm{DS}_{\mathrm{GC}} \mathrm{g}$ & & 0.85 & 1.52 & 2.52 & 0.91 & 1.55 & 2.48 \\
\hline yield $^{\mathrm{h}}$ & & & $77-83$ & $86-74$ & $82-86$ & $74-76$ & $72-75$ & $79-81$ \\
\hline
\end{tabular}


characterization was carried out by elementary analysis (EA), ${ }^{1} \mathrm{H}$ NMR spectroscopy, and infrared spectroscopy (ATR-IR). Gas-liquid chromatography (GLC) in combination with mass spectrometry (MS) was employed for the analysis of glucose derivatives after depolymerization of the cyanoethylglucans.

The DS of heterogenic atoms containing polysaccharide derivatives can be followed by elementary analysis. To avoid misinterpretations due to impurities of the polymer sample, it should be checked whether the DS usually calculated from the nitrogen content is in accordance with the ratios of the other elements. Therefore, we evaluated the $\mathrm{DS}_{\mathrm{EA}}$ from the $\mathrm{N}$ content and additionally from the $\mathrm{C} / \mathrm{N}$ ratio. Results are given in Table 1. $\mathrm{DS}_{\mathrm{EA}(\mathrm{C} / \mathrm{N})}$ was 0 to $7.8 \%$ higher than $\mathrm{DS}_{\mathrm{EA}(\mathrm{N})}$. In the following the functionalized glucans were investigated by ATR-IR spectroscopy. The characteristic $\mathrm{C} \equiv \mathrm{N}$ stretching vibration was detected at $2250 \mathrm{~cm}^{-1}$ increasing with DS, while the intensity of the $\mathrm{OH}$ stretching $\left(3400 \mathrm{~cm}^{-1}\right)$ decreased, with the maximum being shifted to higher wavenumbers ( $\rightarrow$ less hydrogen bonding). No side products, such as amides or carboxylates (as hydrolysis products of nitrile groups), or only traces thereof, were observed [21]. ATR-IR spectra of native dextran and the cyanoethyl ethers are shown in Figure 2. Figure 3 shows the ATR-IR spectra for pullulan and the corresponding cyanoethyl ethers.

${ }^{1} \mathrm{H}$ NMR spectroscopy is a versatile and fast method for qualitative and quantitative structural analysis. Figure 4 presents the ${ }^{1} \mathrm{H}$ NMR spectra of cyanoethyldextrans CED-2 and CED-3 in comparison with the unmodified polysaccharide. DMSO- $d_{6}$ was used as a solvent for the derivatives with a DS $>2$ and $\mathrm{D}_{2} \mathrm{O}$ for the less-substituted polyglucans.

The spectra of $O$-cyanoethylglucans show strong peak broadening and therefore worse resolution compared to the starting material (Figure 4 and Figure 5). The signal at $2.82 \mathrm{ppm}$ in $\mathrm{D}_{2} \mathrm{O}$ and $2.75 \mathrm{ppm}$ in DMSO is assigned to the methylene group

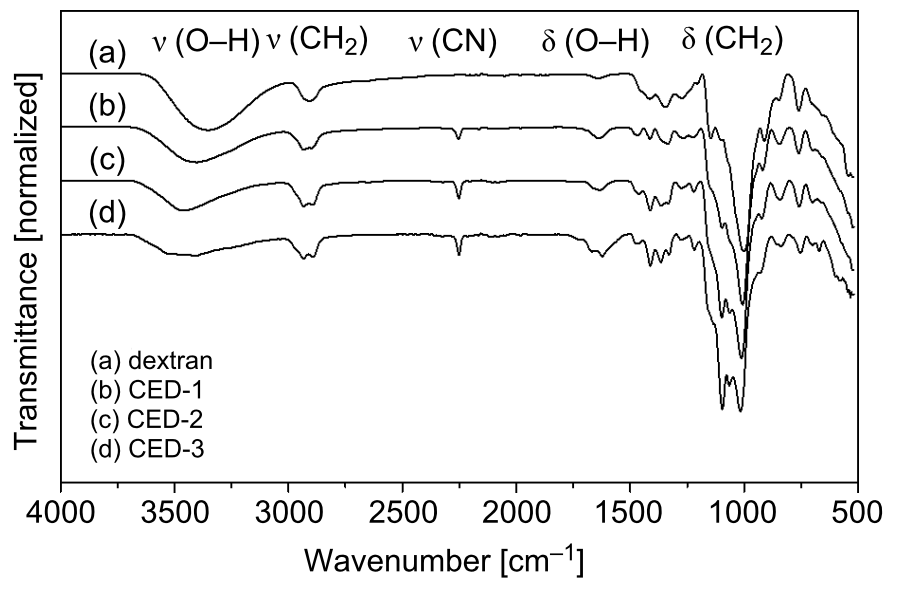

Figure 2: ATR-IR spectra of (a) dextran, $6 \mathrm{kDa}$, and cyanoethyldextrans (b-d) CED-1-3.

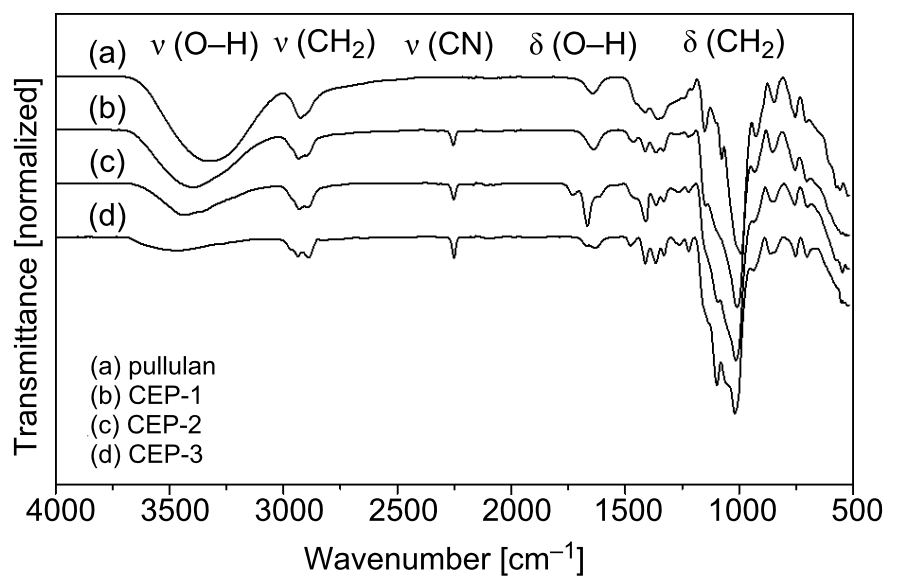

Figure 3: ATR-IR spectra of (a) pullulan, $100 \mathrm{kDa}$, and cyanoethylpullulans (b-d) CEP-1-3. 


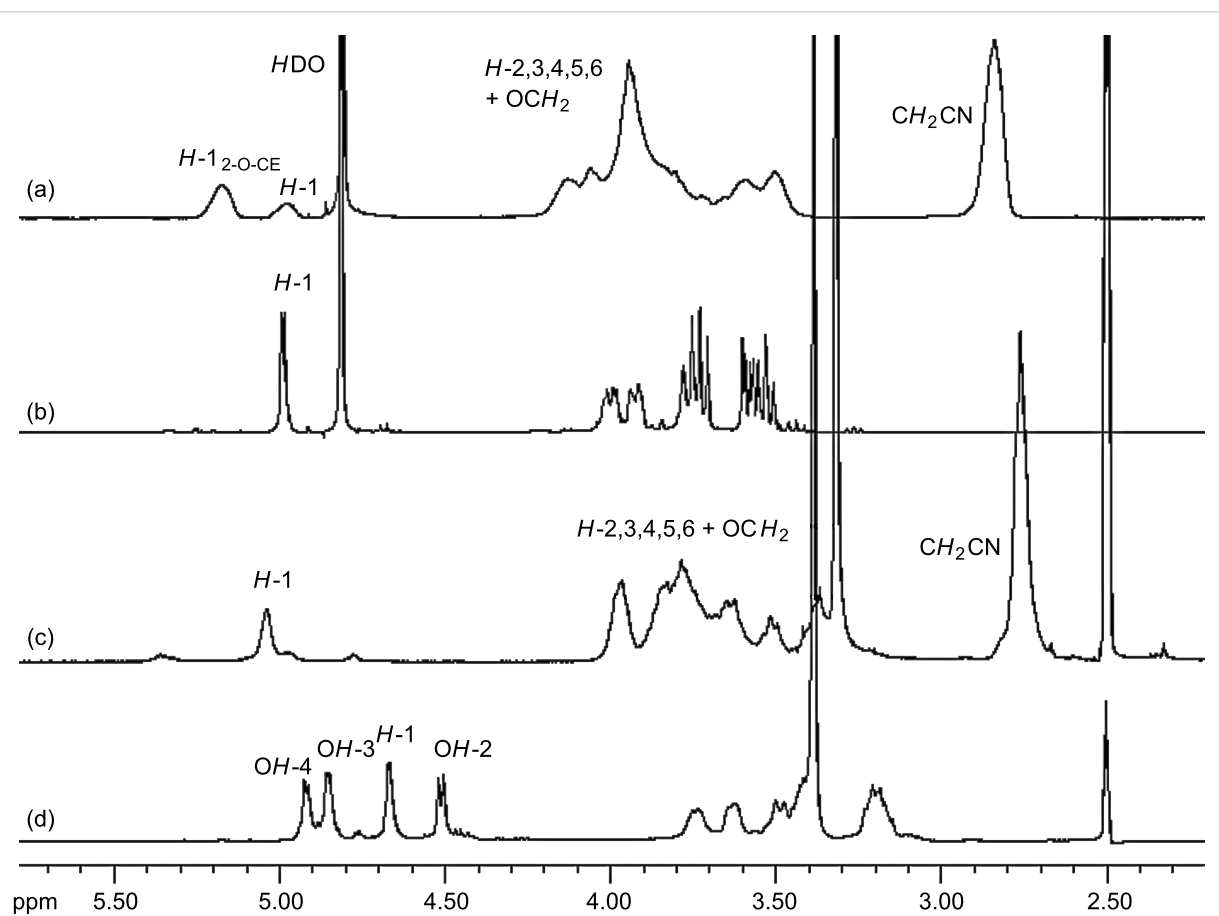

Figure 4: ${ }^{1} \mathrm{H}$ NMR spectra $(300 \mathrm{MHz})$ of $(a) C E D-2\left(D_{N M R(1)}=1.81\right)$ in $\mathrm{D}_{2} \mathrm{O}$; (b) dextran, native in $\mathrm{D}_{2} \mathrm{O}$; (c) CED-3 $\left(\mathrm{DS} \mathrm{S}_{\mathrm{NMR}(1)}=2.37\right)$ in DMSO- $d_{6}$; (d) dextran, native in DMSO- $d_{6}$; calibrated with solvent signals.

adjacent to the cyano function $\left(\mathrm{CH}_{2}-\mathrm{CN}\right)$. The remaining protons of the cyanoethyl substituent overlap with sugar ring protons in the range of 3.3-4.2 ppm. As a result of 2- $O$-substitution, $H-1$ is shifted downfield. For the $\alpha-1 \rightarrow 6$-glucosyl residues of dextrans (in $\mathrm{D}_{2} \mathrm{O}$ ) it is shifted from 4.97 to $5.16 \mathrm{ppm}$. The average DS value was calculated from the ratio of the signal integrals of the methylene group adjacent to the nitrile group, to the summarized integrals of $H-1$ (Equation 1). DS evaluation in position 2 is also possible (Equation 2).

$$
\begin{gathered}
\mathrm{DS}_{\mathrm{CE}}=\frac{\frac{1}{2} \int \mathrm{CH}_{2} \mathrm{CN}}{\int H-1+\int H-1_{2-\mathrm{O}-\mathrm{CE}}} \\
\mathrm{DS}_{2-\mathrm{O}-\mathrm{CE}}=\frac{\int H-1_{2-\mathrm{O}-\mathrm{CE}}}{\int H-1+\int H-1_{2-\mathrm{O}-\mathrm{CE}}}
\end{gathered}
$$

For cyanoethylated pullulan, the situation is more complex as is obvious from Figure 5. While the NMR spectrum of the native pullulan in $\mathrm{D}_{2} \mathrm{O}$ is well resolved with $H-1$ signals at 4.90 $(\alpha-1 \rightarrow 6$-Glc, ring C), 5.30 ppm $(\alpha-1 \rightarrow 4$-Glc, ring A) $(\alpha-1 \rightarrow 4$ Glc, ring B), the signals are shifted downfield by $O$-cyanoethylation and peak broadening occurs, probably due to a poorer solution state of the much more hydrophobic derivatives, and higher viscosity. The region of the anomeric protons becomes very complex and is difficult to integrate. It is assumed that for the 2-O-cyanoethylglucoses, the $H-1$ of the glucosyl residues A, $\mathrm{B}$ and $\mathrm{C}$ (Figure 1) are differentiated by ${ }^{1} \mathrm{H}$ NMR spectroscopy. In DMSO the $\mathrm{OH}$ resonances overlap with $H$-1 protons (Figure 5c and Figure 5d) [36]. The signals are shifted by substitution and the resolution becomes poor. Nevertheless, DS can alternatively be estimated from the integral of the CE-methylene group at 2.82 and the sugar ring protons, which are corrected for the equal contribution by the CE substituent according to Equation 3.

$$
D S_{C E}=\frac{\frac{1}{2} \int \mathrm{CH}_{2} \mathrm{CN}}{\frac{1}{6}\left(\int H 2,3,4,5,6_{a, b}-\int \mathrm{CH}_{2} \mathrm{CN}\right)}
$$

To gain more detailed insight into the distribution of substituents in the glucosyl units, the cyanoethylated glucans were hydrolyzed and subsequently trimethylsilylated. The resulting trimethylsilyl $O$-cyanoethyl- $O$-trimethylsilyl- $\alpha, \beta-\mathrm{D}$ glucosides were analyzed by GLC-FID [3]. Peaks were assigned according to the position of cyanoethylation by GC-MS (Figure 6). Pairs of $\alpha$ - and $\beta$-glucosides were observed for each pattern. In addition, minor peaks of $O$-carboxyethyl derviatives (as $\mathrm{SiMe}_{3}$ esters) were observed, since hydrolysis of the cyano group could not be avoided completely. However, quantitative evaluation, with and without considering these side 


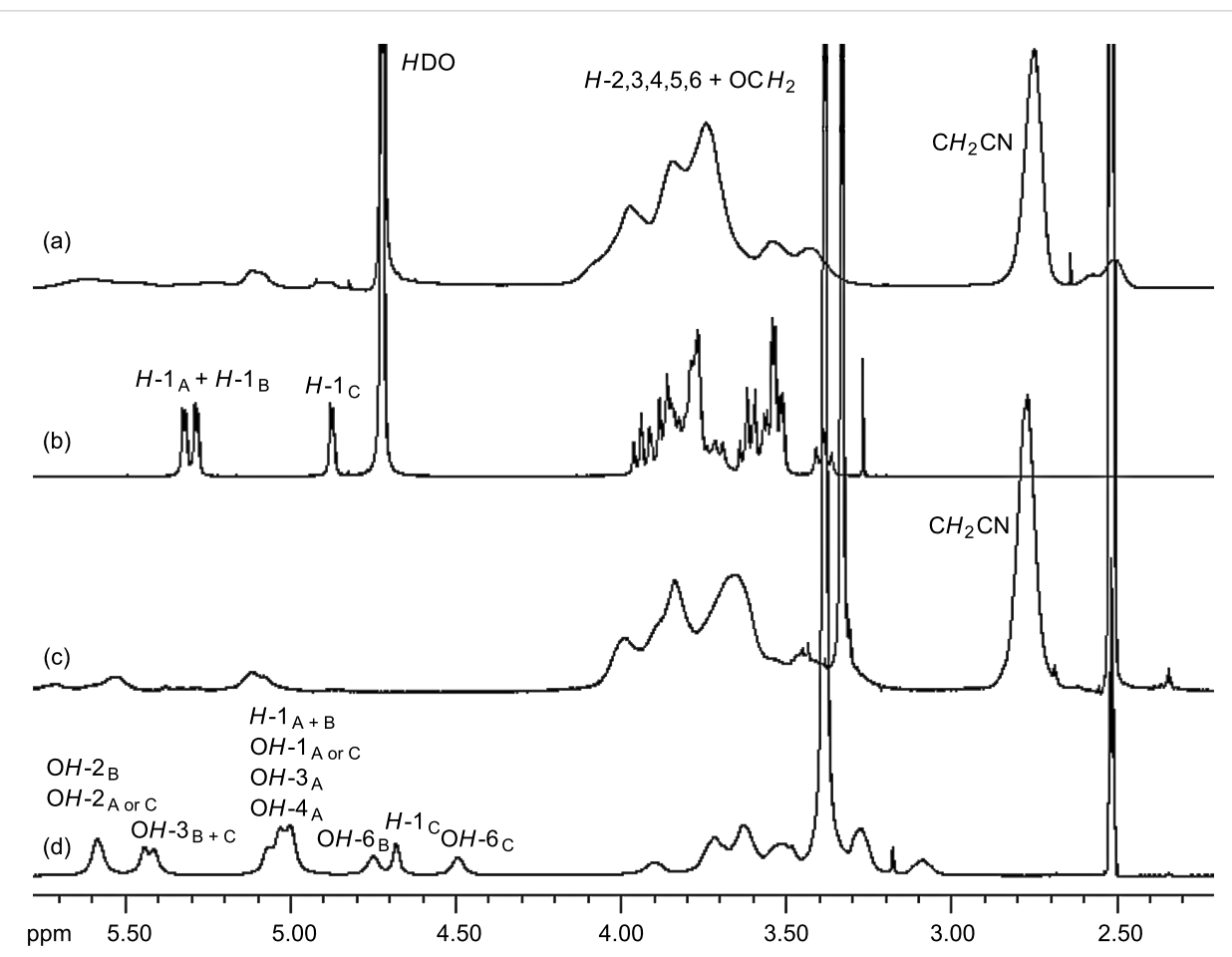

Figure 5: ${ }^{1} \mathrm{H}$ NMR spectra $(400 \mathrm{MHz})$ of $(a) C E P-2\left(\mathrm{DS}_{\mathrm{NMR}(3)}=1.31\right)$ in $\mathrm{D}_{2} \mathrm{O}$; (b) pullulan, native in $\mathrm{D}_{2} \mathrm{O}$; (c) CEP-3 $\left(\mathrm{DS} \mathrm{S}_{\mathrm{NMR}(3)}=2.43\right)$ in DMSO- $d_{6}$; (d) pullulan, native in DMSO- $d_{6}$; calibrated with solvent signals.

products, did not effect significant differences in the relative substituent distribution, but only an underestimation of the average $\mathrm{DS}_{\mathrm{GC}}$ of up to $12 \%$. Obviously, the rate of hydrolysis of the peripheral $\mathrm{CN}$ groups is decoupled from the carbohydrate backbone and thus independent of the position. Both $\mathrm{DS}_{\mathrm{GC}}$ values are given in Table 1 .

Based on monomer analysis, a statistical evaluation can be performed. Neglecting 6-O-substitution at terminal residues, eight different constituents are expected for cyanoethyldextran: unsubstituted $\left(s_{0}\right)$, monosubstituted at position 2,3 , or $4\left(s_{2}\right.$, $\left.s_{3}, s_{4}\right)$, disubstituted at positions $2,3,2,4$, or $3,4\left(s_{23}, s_{24}, s_{34}\right)$, and 2,3,4-tri- $O$-substituted glucose $\left(s_{234}\right)$. For pullulan, 6-, 2,6-, 3,6-, and 2,3,6-patterns must be additionally considered. With the exception of 6-O-CE-glc, these patterns were not detected for cyanoethyldextrans. The tetra- $O$-substituted glucosyl unit $\left(s_{2346}\right)$, a possible product of the terminal residue, was neither detected for pullulan nor for dextran ethers.

For the statistical evaluation of the monomer data of cyanoethyldextrans, substitution at O-6 was neglected, i.e., 6,n$O$-substituted glucosyl units were added to the $n$ - $O$-substituted group. The number of monomer patterns considered was thus reduced to eight. In case of pullulan, consisting of $\alpha-1 \rightarrow 6$ linked maltotriose repeating units (Figure 1), patterns including 4- or 6-O-substitution were weighted according to their avail- ability of 1:2 calculated for a random distribution. Random patterns were calculated considering the partial DS values determined for the different $\mathrm{OH}$ groups. The results of monomer analysis and statistical evaluation are summarized in Table 2. The peak areas from GLC-FID measurements were corrected according to the effective response concept [37].

CED-1 and CEP-1, modified without the cosolvent acetone, showed the lowest DS values. Upon addition of $1 \mathrm{~mL}$ acetone (Table 1), while the other parameters of the reaction were maintained, the DS value increased by nearly $100 \%$ (CED-2 and CEP-2). The highest DS values were achieved under the conditions according to Onda (CED-3 and CEP-3) [4]. In this approach acetone and acrylonitrile were used in the same ratio. The base concentration and reaction time were increased ( 2 equiv $\mathrm{NaOH} / \mathrm{glc}$ ) and the reaction was performed at $\mathrm{rt}$. Acetone acts as a solvent intermediator and probably improves the contact of acrylonitrile and glucan. In addition, it keeps the product in a solution state, even at increasing DS.

The results of GLC analysis demonstrate that the thermodynamically controlled regioselectivity for the cyanoethylation follows the order O-2 $>$ O-4 $>$ O-3 for all CE-dextrans. The order of partial DS values for CE-pullulans changes with increasing DS (and thus with the reaction conditions), in favor of the primary 6-OH. Considering the relative proportions of the $\mathrm{OH}$ groups, 

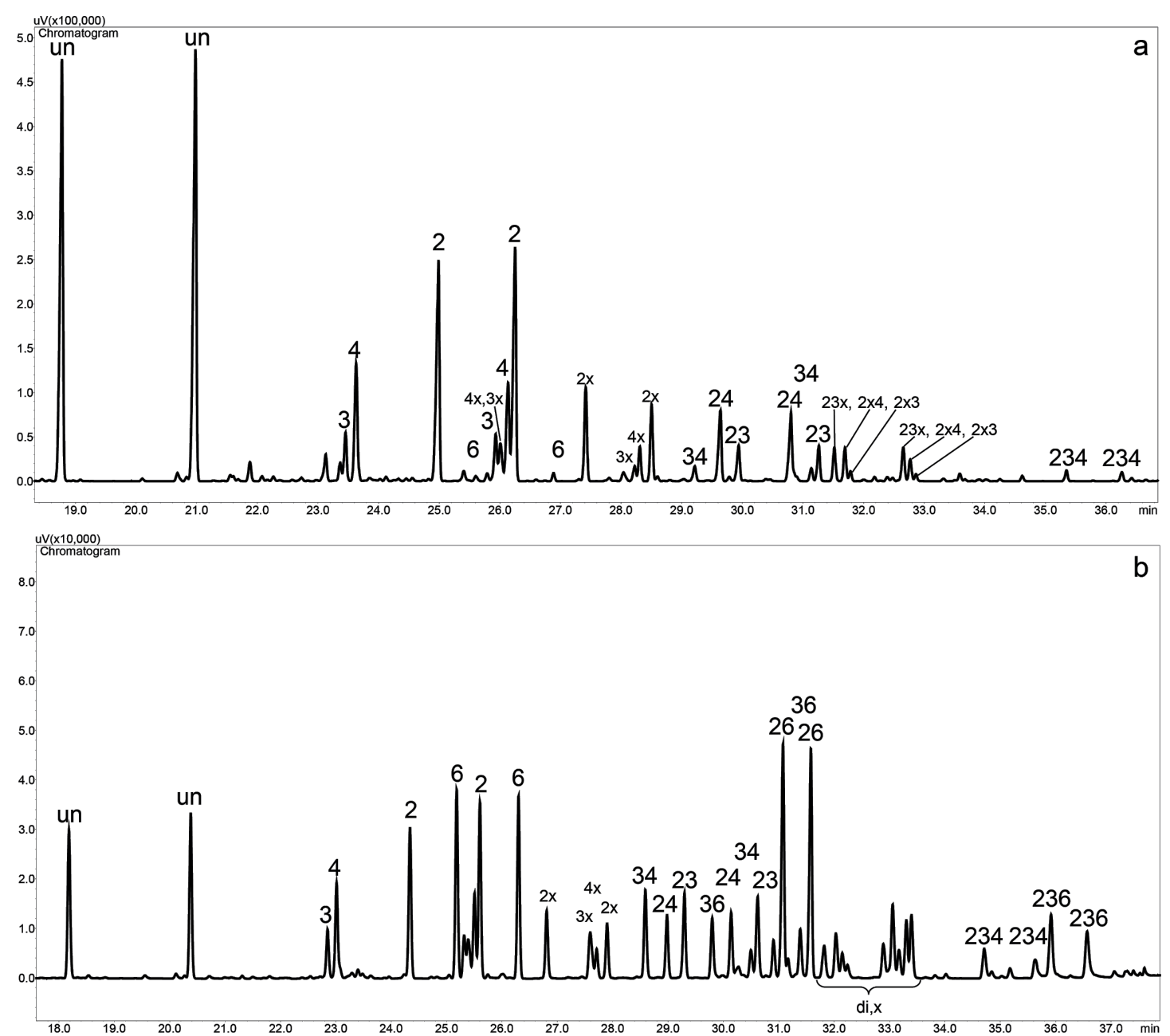

Figure 6: Gas chromatogram of hydrolyzed and trimethylsilylated cyanoethylglucans; (a) $C E D-1\left(D S_{G C}=0.74\right) ;(b) C E P-2(D S G C=1.52) ; x=$ side products with hydrolyzed cyanonitrile, i.e., carboxyethyl-TMS-ester group; di, $x=3 x, 6 \mathrm{CE}, 2$ or $4 x, \mathrm{CE}, 2 \mathrm{x}, 6 \mathrm{CE}, 3 \mathrm{x}, 6 \mathrm{CE}, 2$ or 4x,CE, 2x,6CE); un: unsubstituted glc.

Table 2: Monomer composition [mol \%] $\left(s_{n}\right)$ of un-, mono-, di- and tri-substituted glucose units $\left(c_{n}\right)$ (DS $\mathrm{GC}_{\mathrm{GC}}$ calculated without $O$-carboxyethyl derviatives) and partial degrees of substitution $\left(x_{n}\right)$ at position $2,3,4,6 ; H_{1}$ : heterogeneity parameter.

\begin{tabular}{lrrrrrrr} 
& & CED-1 & CED-2 & CED-3 & CEP-1 & CEP-2 & CEP-3 \\
\hline monomer & $s_{0}$ & 43.20 & 14.97 & 2.29 & 37.90 & 11.32 & 0.49 \\
composition & $s_{2}$ & 24.61 & 21.76 & 2.92 & 25.39 & 11.82 & 1.05 \\
[mol \%] & $s_{3}$ & 4.85 & 5.39 & 2.65 & 4.28 & 3.52 & 0.88 \\
& $s_{4}$ & 11.86 & 12.19 & 3.38 & 3.65 & 6.86 & 1.26 \\
& $s_{6}$ & & & & 9.02 & 13.98 & 6.63 \\
& $s_{23}$ & 4.02 & 11.41 & 13.58 & 2.94 & 7.03 & 3.69 \\
& $s_{24}$ & 8.46 & 21.36 & 6.80 & 2.97 & 5.23 & 1.12 \\
& $s_{26}$ & & & & 6.28 & 19.66 & 15.07 \\
& $s_{34}$ & 1.80 & 4.46 & 15.39 & 4.20 & 5.26 & 6.54 \\
& $s_{36}$ & & & & 1.62 & 4.81 & 10.14 \\
& $s_{234}$ & 1.20 & 8.46 & 52.99 & 0.33 & 3.34 & 16.53 \\
& $s_{236}$ & & & & 1.41 & 7.17 & 36.60
\end{tabular}


Table 2: Monomer composition [mol \%] $\left(s_{n}\right)$ of un-, mono-, di- and tri-substituted glucose units $\left(c_{n}\right)$ (DS ${ }_{\mathrm{GC}}$ calculated without $O$-carboxyethyl derviatives) and partial degrees of substitution $\left(x_{n}\right)$ at position $2,3,4,6 ; H_{1}$ : heterogeneity parameter. (continued)

\begin{tabular}{|c|c|c|c|c|c|c|c|}
\hline number of & $c_{0}$ & 43.20 & 14.97 & 2.29 & 37.90 & 11.32 & 0.49 \\
\hline \multirow[t]{3}{*}{ cyanoethyl groups } & $c_{1}$ & 41.31 & 39.34 & 8.95 & 42.35 & 36.17 & 9.82 \\
\hline & $c_{2}$ & 14.28 & 37.23 & 35.78 & 18.01 & 41.99 & 36.55 \\
\hline & $c_{3}$ & 1.20 & 8.46 & 52.99 & 1.74 & 10.51 & 53.14 \\
\hline \multirow[t]{10}{*}{ partial DS values } & $x_{2}$ & 0.38 & 0.63 & 0.76 & 0.39 & 0.54 & 0.74 \\
\hline & $\%$ & 52.12 & 45.27 & 31.85 & 47.05 & 35.76 & 30.56 \\
\hline & $x_{3}$ & 0.12 & 0.30 & 0.85 & 0.15 & 0.31 & 0.74 \\
\hline & $\%$ & 16.15 & 21.35 & 35.34 & 17.69 & 20.52 & 30.70 \\
\hline & $x_{4}$ & 0.23 & 0.46 & 0.79 & 0.11 & 0.21 & 0.25 \\
\hline & $\%$ & 31.73 & 33.38 & 32.81 & 13.35 & 13.64 & 10.50 \\
\hline & $x_{6}$ & & & & 0.18 & 0.46 & 0.68 \\
\hline & $\%$ & & & & 21.92 & 30.07 & 28.24 \\
\hline & DS & 0.74 & 1.39 & 2.40 & 0.84 & 1.52 & 2.42 \\
\hline & $H_{1}^{a}$ & 0.30 & 0.39 & 0.51 & 0.43 & 0.43 & 0.55 \\
\hline
\end{tabular}

a $H_{1}=\sqrt{\sum_{\mathrm{i}=0}^{234} \Delta s_{i}^{2}} / n, \Delta s_{\mathrm{i}}=s_{\mathrm{i}}$ (theor.) $-s_{\mathrm{i}}$, with $s_{\mathrm{i}}=$ mol fraction of glucose units substituted in position $\mathrm{i}, n=8$ for dextran, $n=12$ for pullulan; (mean values calculated by twofold determination of the molar composition of the corresponding TMS derivatives by GLC-FID).

namely $3: 3: 1: 2$ for $\mathrm{O}-2, \mathrm{O}-3, \mathrm{O}-4$, and $\mathrm{O}-6$, the degree of conversion follows the order O- $6>0-4>0-2>0-3$ for CEP-2 (DS $=1.52$ ), with the three secondary $\mathrm{OH}$ being equalized for CEP-3 (DS = 2.42). Only for CEP-1, with the lowest DS (0.84), the most acidic 2-OH dominates, and 4-OH shows higher conversion than primary O-6. Comparing pullulan with dextran, the preference for 2-O-cyanoethylation is less pronounced in pullulans, in which one third of the 4-OH is "substituted" by the primary 6-OH. In former work, we found a higher preference for 6-O-substitution (50\%) over 2-O-substitution (37\%) for exclusively $\alpha-1 \rightarrow 4$-linked amyloses reacted in an aqueous paste [3]. The heterogeneity parameter $H_{1}$ indicates the average deviation of experimental data from a random distribution, taking into account the relative partial DS values $\left(x_{i}\right)$ found for the various $\mathrm{OH}$ groups. A DS dependency of $H_{1}$ is inherent when employing this equation, since DS is limited to the range of $0-3$. The highest heterogeneity can be calculated at medium DS values of around 1.5. Approximating the limits (DS $=0$ and 3 ), less deviation is possible. The evaluated heterogeneity values are low, as was expected for a thermodynamically controlled reaction [38]. Minor deviations from the random model are within experimental error. Corresponding graphics are shown in Figure 7 and Figure 8.

By all three of the methods applied, similar DS values were obtained. Elementary analysis is a fast method employing the entire material. However, it is important not only to take the nitrogen content for the estimation of DS, but also to check whether the relative amounts of $\mathrm{C}$ and $\mathrm{H}$ are in accordance with this, since the $\mathrm{N}$ content can be lowered by nitrogen-free impurities or be enhanced by residual side products from the reagent. $\mathrm{DS}_{\mathrm{GC}}$ values calculated by including the $O$-carboxyethyl derivatives were in good agreement with the $\mathrm{DS}_{\mathrm{EA}}$. The $\mathrm{DS}_{\mathrm{GC}}$ calculated values without these side products were decreased. This is plausible, since the side reaction mentioned makes the product pattern even more complex and does not allow detection and identification of all minor components, thus discriminating the DS. NMR spectroscopy can be applied to the intact polymer and gives more detailed information than EA. However, broadening and splitting of peaks into different types of $H_{1}$ depending on the position of linkage and substitution makes it difficult to assign and integrate all relevant resonance signals. This is obvious from the differences obtained when employing different signals for the calculation (Equation 1 and Equation 3). Only after depolymerization it was possible to determine the detailed substitution pattern by GLC analysis.

In general, good isolated yields in the range from 72 to $86 \%$ were achieved (Table 1). The DS values strongly increased upon the addition of acetone as a solubility mediator (CED-2 and CEP-2). No side products, such as amides or carboxylates, or only traces thereof, were detectable for the CE glucans, as proved by IR and NMR measurements $\left({ }^{1} \mathrm{H}\right.$ and $\left.{ }^{13} \mathrm{C}\right)$. A homopolymerization of acrylonitrile could be excluded since the $\mathrm{DS}_{\mathrm{EA}}$ from $\mathrm{N}$ and $\mathrm{C} / \mathrm{N}$ were very close and only moderately enhanced compared to the $\mathrm{DS}_{\mathrm{GC}}$. 

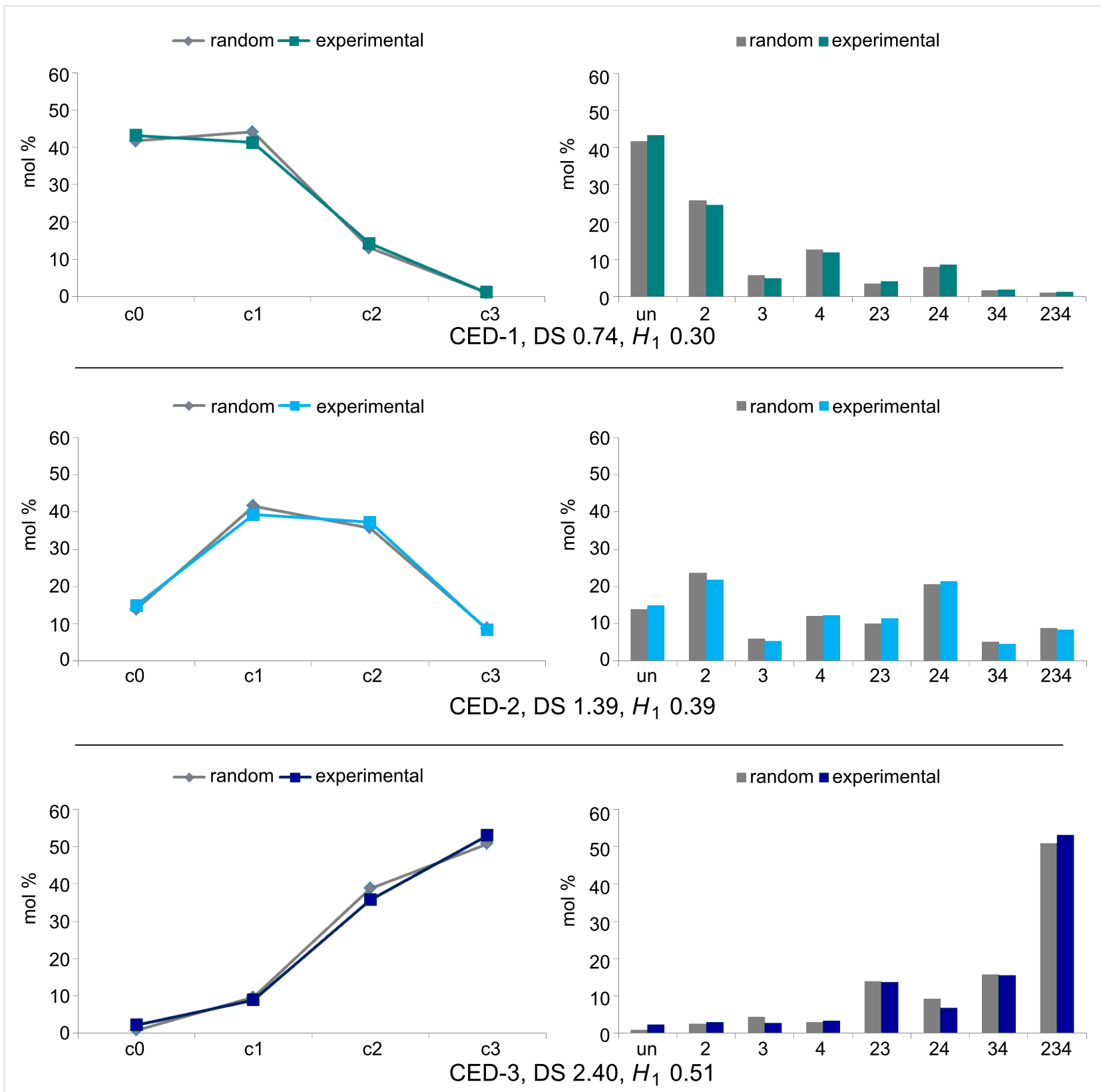

Figure 7: Experimentally determined substituent distribution in the glucosyl units (glc) of cyanoethyldextrans CED-1-3 (blue) compared with a random distribution (gray). Left: $\mathrm{ci}=$ the fraction of i-fold-substituted glucosyl units (mol \%); right: un = unsubstituted glc; the numbers assign the substituted positions, e.g., $234=2,3,4$-tri-O-cyanoethyl glc; $H_{1}$ heterogeneity parameter for the standard deviation as defined in Table 2 .

\section{Nanostructures of cyanoethylglucans}

In the next step the ability of cyanoethylglucans to form nanoparticles was investigated [12-14,39]. DMSO solutions of the cyanoethylpolysaccharides CEP-3 $\left(\mathrm{DS}_{\mathrm{GC}}=2.42\right)$ and CED-3 $\left(\mathrm{DS}_{\mathrm{GC}}=2.40\right)$ were submitted to dialysis against water. Only the derivatives with a DS value $>2$ formed regular particles that were stable in water for several weeks without precipitation [13]. Furthermore, the same procedure was performed in the presence of ferromagnetic iron oxide nanoparticles. The magnetic cores were prepared by a precipitation process of
$\mathrm{Fe}(\mathrm{II})$ and $\mathrm{Fe}$ (III) chlorides (molar ratio 1.7:1.0) with aqueous ammonia solution $[40,41]$. After ultrasonic treatment the resulting particles were fixed with strong magnets and washed with distilled water. Monodisperse and regularly shaped iron oxide nanoparticles were obtained as shown by TEM (Figure 9). The iron concentration of the nanoparticle dispersion, as analyzed with inductively coupled plasma optical emission spectroscopy (ICP-OES), was $37.2 \mathrm{~g} / \mathrm{kg}$. The particle size was calculated by image data processing of the TEM micrograph resulting in a mean diameter of $12.2 \mathrm{~nm} \pm 2.6 \mathrm{~nm}$. The hydro- 


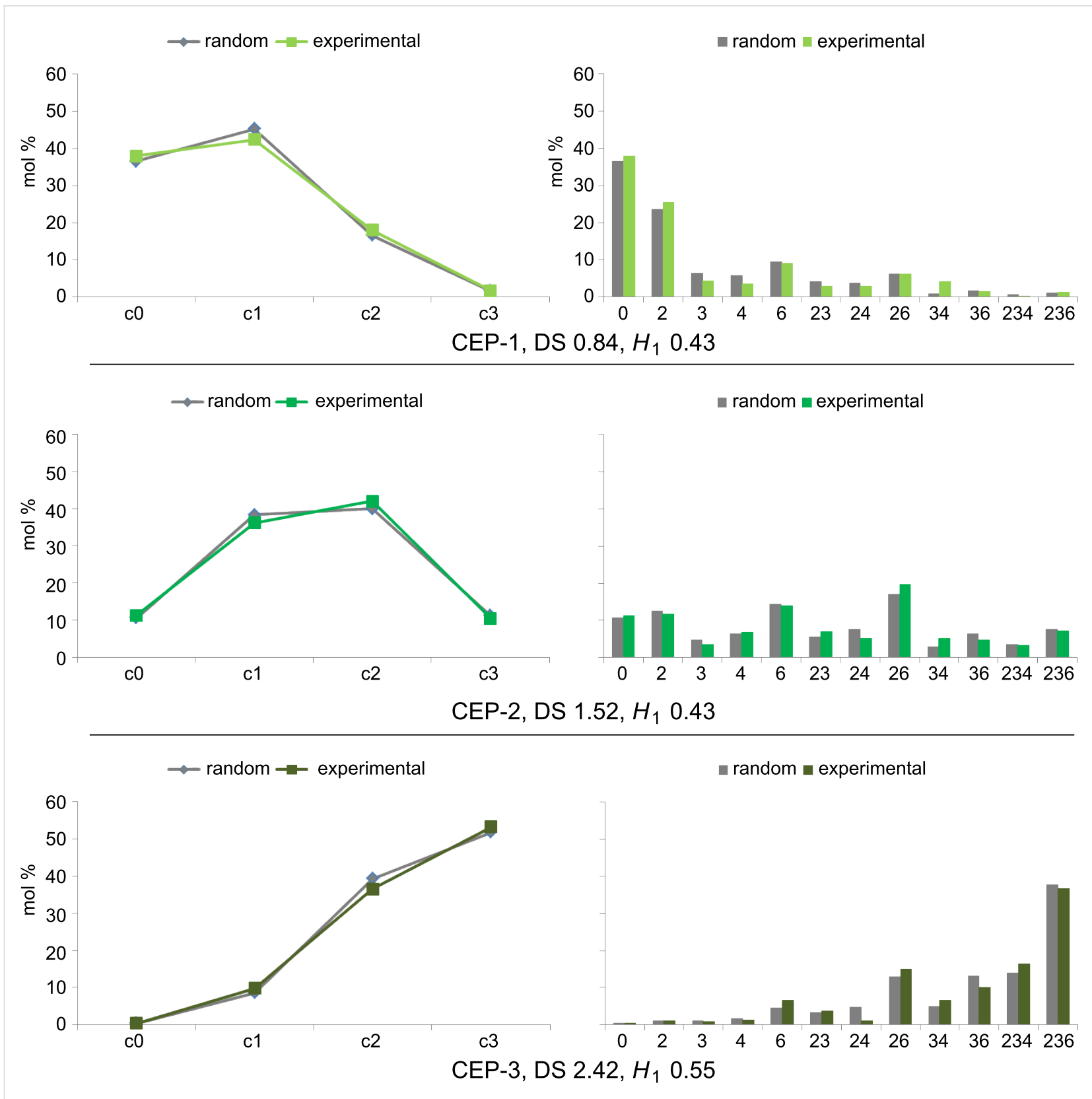

Figure 8: Experimentally determined substituent distribution in the glucosyl units (glc) of cyanoethylpullulans CEP-1-3 (green) compared to a random pattern (gray). Left: $\mathrm{c}_{\mathrm{i}}=$ the fraction of $\mathrm{i}$-fold-substituted glucosyl units $(\mathrm{mol} \%)$; right: un $=$ unsubstituted glc; the numbers assign the substituted positions, e.g., $234=2,3,4$-tri-O-cyanoethyl glc; $H_{1}$ heterogeneity parameter for the standard deviation as defined in Table 2 .

dynamic diameter was estimated at $27 \mathrm{~nm}$ by dynamic light scattering (DLS) measurements. Agglomeration or aggregation processes were prohibited by $\mathrm{pH}$ stabilization. At $\mathrm{pH} 2$ the iron oxide dispersion is stable for several months without precipitation.

After the dialysis process of the high-DS cyanoethyldextran and pullulan $\left(20 \mathrm{mg}, \mathrm{CED}-3, \mathrm{DS}_{\mathrm{GC}}=2.40 ; \mathrm{CEP}-3, \mathrm{DS}_{\mathrm{GC}}=2.42\right)$ the hydrodynamic diameter of the particles was determined by DLS. Additionally, scanning electron microscopy (SEM) micrographs were recorded. Using SEM the morphology of polysaccharide particles is accessible. The parameters and results of the DLS and SEM measurements are summarized in Table 3.

DLS measurements were in good agreement with the evaluation of the electron microscopy images. According to the micrographs, the morphology of the cyanoethyl nanoparticles can be considered as spherical. Representative SEM pictures of CEP-3 + Fe-np (Table 3, entry 2) are shown in Figure 10. 


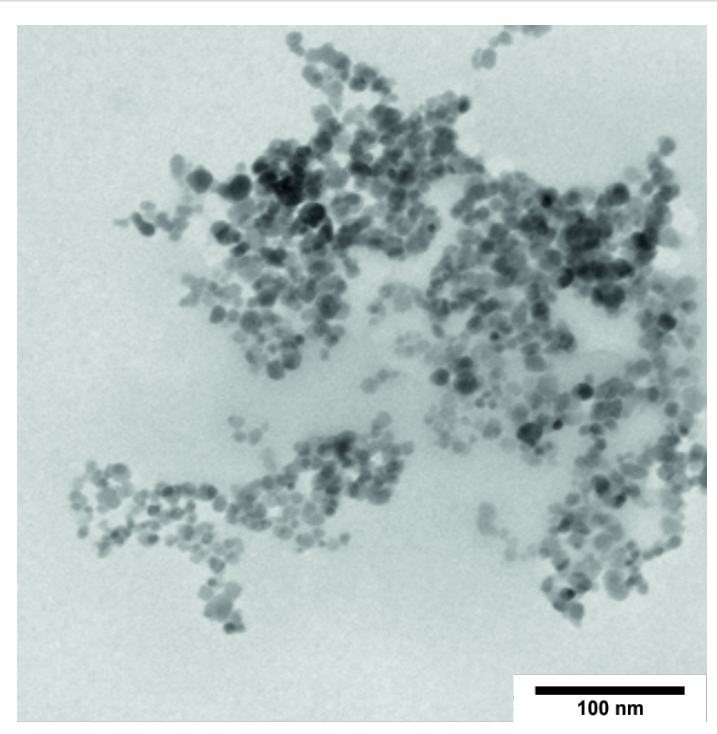

Figure 9: TEM micrograph of iron oxide nanoparticles prepared from an aqueous dispersion.
The influence of different amounts of ferromagnetic nanoparticle dispersion was investigated $(10-200 \mu \mathrm{L}$ or equivalently 0.0067-0.1332 mmol Fe/0.07 mmol glucosyl units, or $0.165 \mathrm{mmol} \mathrm{CE}$ ). Independent preparation of the ferromagnetic nanoparticles has the advantage that nanostructuring can be performed on a small scale. Coprecipitation methods, in which magnetic particles are formed and simultaneously coated, require higher amounts of polymer [42] (up to gram scale) and deliver irregularly shaped particles [13]. Increasing the amount of metal oxide from 0.0133 to $0.1332 \mathrm{mmol}$ iron $(20-200 \mu \mathrm{L})$ with $20 \mathrm{mg}$ polymer $(=0.07 \mathrm{mmol}$ glucosyl units, respective $0.165 \mathrm{mmol}$ CE) resulted in smaller particles (Table 3 ). The upper limit is $200 \mu \mathrm{L}$ ferrofluid $(0.1332 \mathrm{mmol} \mathrm{Fe} / 0.165 \mathrm{mmol}$ $\mathrm{CE})$. Below this limit the whole of the iron core is entrapped. Higher amounts of iron oxide resulted in multimodal, aggregated particles and precipitation. Interestingly, the smallest particles were formed without iron oxide (Table 3, entry 6 and 7, $260 \mathrm{~nm}$, respectively $331 \mathrm{~nm}$ ). Magnetic properties depend on the amount of iron and can be adjusted by varying the

Table 3: Parameters and characterization of nanostructures formed from CED-3 and CEP-3, in the absence and presence of ferromagnetic nanoparticles, by DLS and SEM measurements; $20 \mathrm{mg}$ of cyanoethylglucan was used for each entry (= $0.07 \mathrm{mmol}$ glucosyl units).

\begin{tabular}{|c|c|c|c|c|c|c|}
\hline \multirow[t]{3}{*}{ sample } & \multirow[t]{3}{*}{ CE-glucana } & \multicolumn{2}{|c|}{$\begin{array}{c}\text { iron oxide } \\
\text { nanoparticle dispersion }\end{array}$} & \multicolumn{3}{|c|}{ diameter } \\
\hline & & & & DLS & $\mathrm{SEM} \pm{ }^{b}$ & \\
\hline & & {$[\mu \mathrm{L}]$} & $\mathrm{Fe}[\mathrm{mmol}]$ & {$[\mathrm{nm}]$} & {$[\mathrm{nm}]$} & $\mathrm{No}^{\mathrm{C}}$ \\
\hline 1 & CEP-3 & 10 & 0.0067 & 611 & $613 \pm 174$ & (69) \\
\hline 2 & CEP-3 & 20 & 0.0133 & 399 & $388 \pm 93$ & (335) \\
\hline 3 & CED-3 & 10 & 0.0067 & 337 & $514 \pm 205$ & (92) \\
\hline 4 & CED-3 & 20 & 0.0133 & 444 & $451 \pm 113$ & (27) \\
\hline 5 & CED-3 & 200 & 0.1332 & 252 & - & \\
\hline 6 & CEP-3 & - & - & 241 & $260 \pm 57$ & $(182)$ \\
\hline 7 & CED-3 & - & - & 203 & $331 \pm 71$ & (308) \\
\hline
\end{tabular}

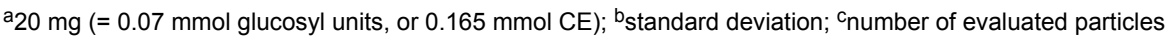

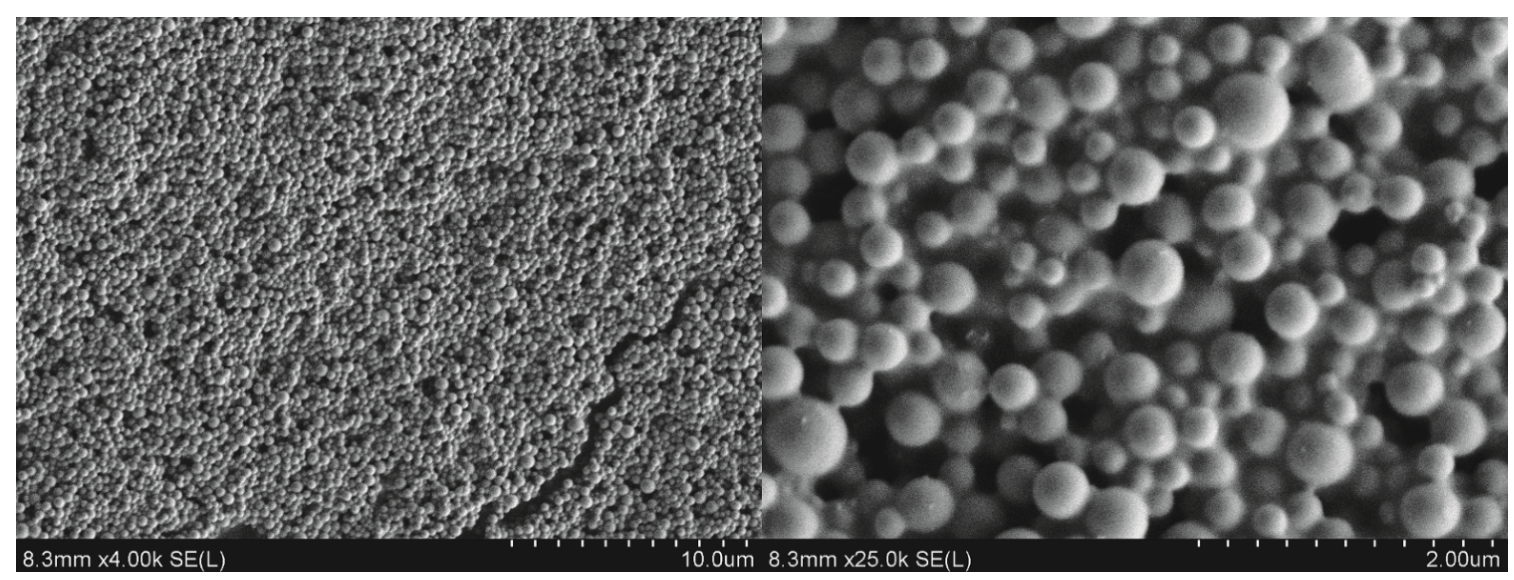

Figure 10: SEM micrographs of CEP-3 with iron oxide nanoparticles, (Table 3, entry 2). 
doping of the glucan particles with iron. Nanostructuring of cyanoethyldextrans and cyanoethylpullulans show no significant differences, although in one case a branched polymer with $6 \mathrm{kDa}$ and on the other hand a $100 \mathrm{kDa}$ linear macromolecule was employed.

Energy-filtered transmission electron microscopy (EF-TEM) is an appropriate method to characterize the structure, morphology and the redox state of metal-containing nanoparticles. Parallel electron energy loss spectroscopy (PEELS) analyses were performed with the uncoated and coated iron oxide nanoparticles in Figure 11. The energy loss functions have been summed from 690 to $740 \mathrm{eV}$. Figure $11 \mathrm{c}$ shows the $\mathrm{Fe} L_{2,3}$ edge spectra of the uncoated iron oxide particles (red line) relative to the polysaccharide coated particles (blue line) and a reference iron, $\mathrm{Fe}(0)$ spectrum (dashed black line) [43]. The intensity is comparably low (Figure 12c) due to the particle size, exceeding the ideal thickness of 30 to $40 \mathrm{~nm}$ for EELS analysis. Nevertheless, a typical intensity profile of Fe $L_{2,3}$ can be seen, at an energy resolution of $1.2 \mathrm{eV}$. The uncoated metal oxide particles show
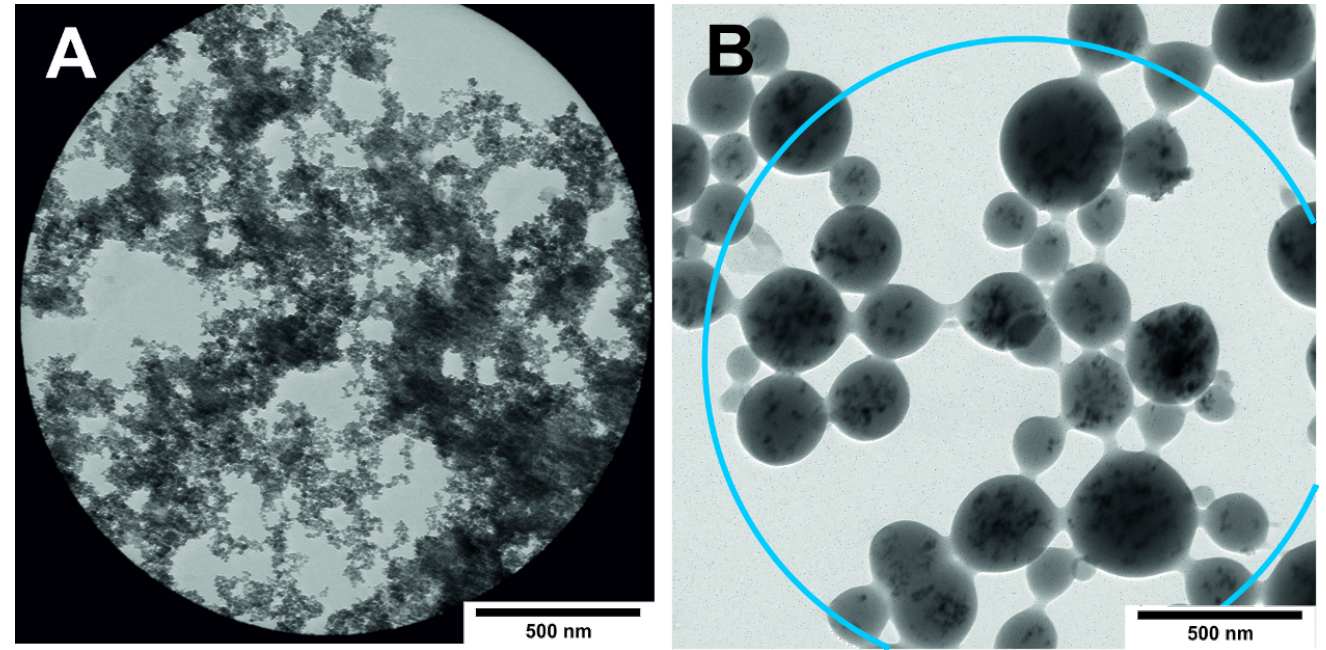

Fe-nps without and with glucan coat (+ Fe-atlas)

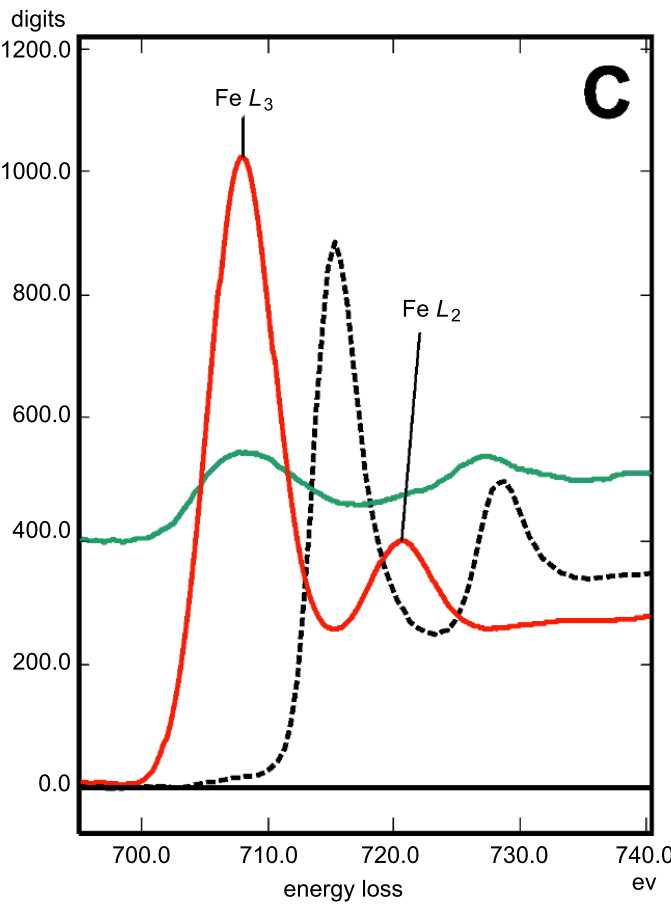

Figure 11: TEM micrograph of (a) uncoated iron oxide nanoparticles; (b) of CEP-3 + iron oxide nanoparticles (no stain), Table 3, entry 1; (c) PEELS measurements of uncoated iron oxide particles (red line), polysaccharide coated particles (blue line) and the Fe(0) atlas reference spectrum (black, dashed line); PEELS measuring areas are shown as aperture in A and circle in B; for details see text. 
maxima of $708.2 \mathrm{eV}$ and $720.7 \mathrm{eV}$ for the $L_{3}$ respective $L_{2}$ edge. In the case of the coated particles, the maxima were determined at $711.4 \mathrm{eV}$ for $L_{3}$ and $728.9 \mathrm{eV}$ for the $\mathrm{L}_{2}$ edge, showing a significant chemical shift, and differences in the spin orbit splitting, i.e., $17.5 \mathrm{eV}$ for coated iron oxide cores versus $12.5 \mathrm{eV}$ for noncoated particles were observed, based on individual measurements. The $L_{3}-L_{2}$ peak maxima distance is defined as the spin orbit splitting for "white-line" elements, such as transition elements and lanthanides, and the $L_{3} / L_{2}$ ratio is indicative of the oxidation state of the element $[44,45]$. Cressey described the possibility to characterize multiple valence states of $3 d$ metals by $L$-edge spectra [46]. By comparing our data with theirs, it is shown that $\mathrm{Fe}^{2+}$ and $\mathrm{Fe}^{3+}$ are present. The spin orbit splitting reflects the influence of the electronic state of the iron oxide core and obviously an interaction with the nitrile groups should be considered $[45,47]$.

Entrapping of iron oxide cores during the carbohydrate nanostructuring process is proven by the electron micrographs. Figure 12 shows the net iron distribution, colored red, in the multicore particles in detail. Due to the material thickness, which is beyond the ideal $30-40 \mathrm{~nm}$, common for EELS measurements, only iron oxide particles near the surface show strong intensity signals. No free iron particles were detected on the carbon foil of the electron microscopic grid or in the waste water after the dialysis step, proving that all of the iron was specifically bound by the cyanoethylglucans. The hydrophobic cyanoethyl groups are expected to "hide" inside the particles, but depending on the distribution of these residues, some can also be directed towards the water phase. These substituents may bind iron oxide particles additionally. This observation could indicate that some cyanoethyl groups are available for further transformation of the outer sugar shell, e.g., amino functionalization followed by coupling with bioactive molecules. In conclusion, it was shown, that the magnetic iron cores were captured by the cyanoethyl-functionalized polysaccharides.

\section{Conclusion}

Cyanoethylation by Michael addition is a versatile tool for polysaccharide modification. The hydrophobic substituents were introduced up to a DS of ca. 2.4 through choice of the appropriate conditions. Average reactivity of the $\alpha$-glucans dextran and pullulan was very similar. The order of substitution was O-2 $>$ O-4 $>$ O-3 for dextran, while the relative degree of conversion changed with the DS from O-2 $>$ O-4 $>$ O-6 $>$ O-3, in favor of primary O-6 for pullulan. The substituents present are randomly distributed in the glucosyl units, which is typical for reversible reactions and always favored in aqueous systems. High cyanoethylated glucans form regularly shaped nanostructures with diameters in the range of 260 to $613 \mathrm{~nm}$. When dialysis was performed in the presence of ferromagnetic nanoparti-

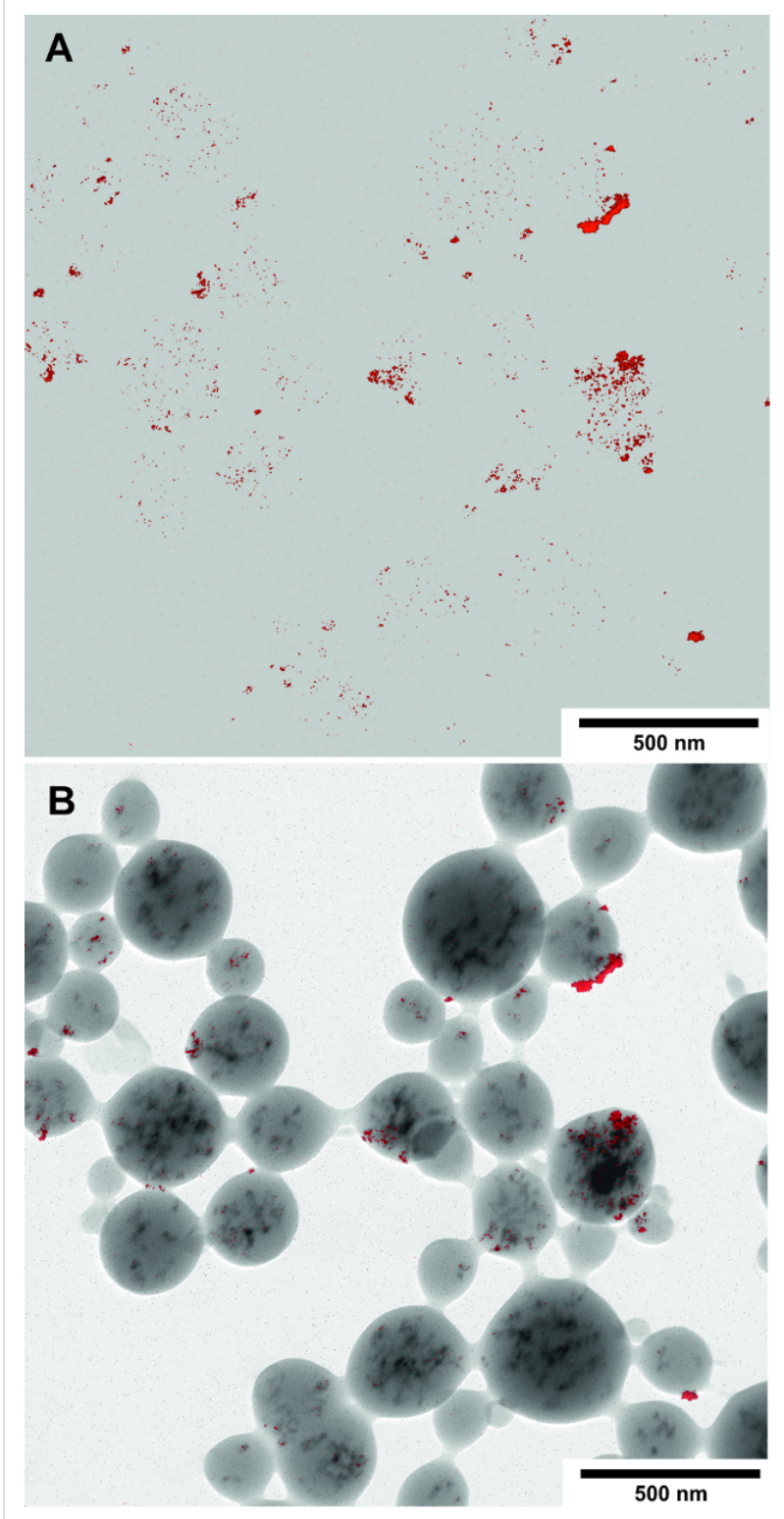

Figure 12: ESI Fe distribution maps of CEP-3 with iron oxide nanoparticle (Table 3, entry 1). (A) Net Fe, shown in red. Because of the signal dimensions, much of the signal intensity is lost, leading to only a weak mapping signal within the corresponding particles; (B) Fe map (red) overlaid on the zero-loss image.

cles, glucan-coated multicore ferromagnetic nanostructures were formed. Quantitative entrapment of iron oxide during dialysis is obviously based on interactions of the cyanoethyl residues with the iron oxide core particles, as is indicated by TEM and PEELS measurements. Further modification of the cyanoethylglucans and their respective nanostructures by transformation to aminopropyl derivatives is under progress. These new particles possess great potential as precursors for aminofunctionalized, magnetic architectures and electrochemical applications. 


\section{Experimental Materials}

Dextran from Leuconostoc ssp. (6 kDa) and pullulan (100 kDa) were purchased from Fluka. Acrylonitrile (AN) was supplied from Janssen. DMSO [puriss, absolute, over molecular sieves $\left(\mathrm{H}_{2} \mathrm{O} \leq 0.01 \%\right), \geq 99.5 \%$ (GC)] was obtained from SigmaAldrich. Deionized water was used. Dialysis was performed with molecular porous dialysis membranes (molecular weight cut off $3.5 \mathrm{kDa}$ ) from Spectrum Laboratories. Bidistilled water was chosen for ICP-OES sample preparation.

\section{Instrumentation}

${ }^{1} \mathrm{H}$ NMR spectra were acquired on a Bruker AMX 300 spectrometer or a Bruker AMX $400 \mathrm{MHz}$ Advance spectrometer at $\mathrm{rt}$ (around $5 \mathrm{mg}$ sample in $\mathrm{D}_{2} \mathrm{O}$ or DMSO- $d_{6}$ ). Chemical shifts are given in ppm relative to the residual solvent signals. ATR-IR spectra were recorded by using a Bruker Tensor 27 attenuated total reflectance infrared (ATR-IR) spectrometer. Elementary analysis (EA) was performed on a Thermoquest EA 1112 analyser. The data given is always the average of two measurements.

Gas-liquid chromatography (GLC) analysis was carried out with a GLC-FID instrument Shimadzu GC 2010 with a Phenomenex Zebron ZB5-MS column (30 m, i.d. $0.25 \mathrm{~mm}$, film thickness $0.25 \mathrm{~mm}$ and $1.5 \mathrm{~m}) . \mathrm{H}_{2}\left(40 \mathrm{~cm} \mathrm{~s}^{-1}\right.$, linear velocity mode) was used as a carrier gas. Data were recorded with a Shimadzu GC Solution Chromatography Data System (version 2.3). Peaks were identified by gas chromatography/mass spectrometry (GLC-MS) analysis. Conditions: injector $250{ }^{\circ} \mathrm{C}$, temperature program: $60{ }^{\circ} \mathrm{C}(1 \mathrm{~min}) ; 20{ }^{\circ} \mathrm{C} / \mathrm{min}$ to $130{ }^{\circ} \mathrm{C}$, $4{ }^{\circ} \mathrm{C} / \mathrm{min}$ to $260{ }^{\circ} \mathrm{C}, 50{ }^{\circ} \mathrm{C} / \mathrm{min}$ to $310{ }^{\circ} \mathrm{C}(10 \mathrm{~min})$, splitless. GLC-MS: Agilent 6890 GC (ZB5-MS column, $30 \mathrm{~m}$, inner diameter $0.25 \mathrm{~mm}$, film thickness $0.25 \mathrm{~mm}$ and $1.5 \mathrm{~m}$ ) and a JEOL GC mate II bench-top double-focusing magnetic sector mass spectrometer. The iron content was determined with a Radialen ICP-OEC Vista MPX, from Varian, (power $1.20 \mathrm{~kW}$, plasma gas $15 \mathrm{~L} / \mathrm{min}$ (Ar), auxiliary gas $1.5 \mathrm{~L} / \mathrm{min}$ (Ar), atomizer pressure $240 \mathrm{kPa}$, pump speed $20 \mathrm{rps}$ ). Atom emission lines: ion emission lines: 234.350/238.204/239.563/259.940/ 260.709/261.187 nm, and internal reference line: Ar, $470.067 \mathrm{~nm}$. Sample preparation: $0.408 \mathrm{~g}$ iron nanoparticle dispersion was dissolved by adding $5 \mathrm{~mL} \mathrm{HCl} \mathrm{(37 \% )} \mathrm{and} \mathrm{subse-}$ quently diluted to $100 \mathrm{~mL}$ with bidistilled water (ultrapure). Calibration was carried out with an external standard solution: Fe $10.000 \mathrm{mg} / \mathrm{L}$ (Specpure, Fa. Alfa Aesar).

\section{Particle size determination}

The hydrodynamic size was determined by using a Zetasizer Ver 6.0.1, Malvern Instruments Ltd. Scanning electron micrographs were recorded with a Hitachi S-4800 FE-SEM (Tokyo,
Japan) at KTH, Sweden. Samples were prepared by putting a drop of each sample on the carbon film covered the metal studs and allowing it to dry. Samples were kept for at least $48 \mathrm{~h}$ in the desiccator prior to the analysis. Transmission electron micrographs were obtained by using a EF-TEM Libra 120 plus Zeiss microscope operated at $120 \mathrm{kV}$. The samples were adsorbed to a hydrophilized carbonfilm, which was supported by a $\mathrm{Cu}$ grid (carbon only, copper 300 square mesh) and dried at rt. All images, PEELS and ESI-sets were recorded with a $2 \times 2 \mathrm{k}$ SharpEye cooled CCD camera (Tröndle, Moorenweiss, Germany) and directed by the ITEM software (OSIS, Münster, Germany). PEELS spectra (main settings: emission current = $2 \mu \mathrm{A}$; spectrum magnification $100 \times$; illumination aperture $=$ $0.5 \mathrm{mrad}$; spectrum registration $=5 \mathrm{~s}$;) and ESI series (magnification $12500 \times$; spectrometer entrance aperture $=100 \mu \mathrm{m}$; slit width $=9 \mathrm{eV}$; illumination aperture $=0.8 \mathrm{mrad}$; image registration $=50 \mathrm{~s} ; \mathrm{E}_{\max }: 712 \mathrm{eV}$; W1: $690 \mathrm{eV}$; W2: $660 \mathrm{eV}$; emission current: $2 \mu \mathrm{A}$ ) of $\mathrm{Fe}$ and oxygen were processed, following adaptively the workflow as described by Hedrich et al. [48].

\section{Cyanoethylation \\ Samples with DS $<2$}

The glucan (1200 mg, $7.4 \mathrm{mmol}$ glc $100 \mathrm{kDa}$ pullulan or $6 \mathrm{kDa}$ dextran) was dissolved in water, and $\mathrm{NaOH}(60 \mathrm{mg}, 0,2$ equiv/ glc) and acrylonitrile $(1,941 \mu \mathrm{L}, 4$ equiv/glc) were added. In syntheses of CED-2 and CEP-2 $1 \mathrm{~mL}$, acetone was added. The mixture was stirred at $45^{\circ} \mathrm{C}$ for $30 \mathrm{~min}$. The product was purified from low-molecular-weight reagents and by-products by dialysis and freeze dried.

\section{Samples with DS $>2$}

According to Onda [4], acrylonitrile (4.65 mL, 23 equiv/glc) and acetone $(4.75 \mathrm{~mL})$ were added to a solution of the polysaccharide (500 mg, $3.08 \mathrm{mmol}$ glc $100 \mathrm{kDa}$ pullulan or $6 \mathrm{kDa}$ dextran) in water and $\mathrm{NaOH}$ (250 mg, 2 equiv/glc). The solution was stirred for $24 \mathrm{~h}$ at $\mathrm{rt}$. The product was dissolved by the addition of acetone and precipitated by adding water three times.

Elementary analysis: CED-1: C, 47.65; H, 6.12; N, 5.79; CED2: C, 50.06; H, 5.82; N, 8.53; CED-3: C, 54.60; H, 5.96; N, 12.23; CEP-1: C, 47.08; H, 6.27; N, 5.99; CEP-2: C, 50.10; H, 6.02, N 8.10; CEP-3: C, 54.55; H, 6.23; N, 11.41 .

IR (diamant-ATR): $\tilde{v}=3465$ (s, OH, depending on DS), 2923, 2893 (m, CH, $\mathrm{CH}_{2}$, aliph.), 2252 (w, $\mathrm{C} \equiv \mathrm{N}$, nitrile), 1640 (m, $\mathrm{OH}), 1167,1467,1409,1324,1271$ (m, CH), 1099, 1009 (s, C-O).

${ }^{1} \mathrm{H}$ NMR of CED-1 and CED-2: ${ }^{1} \mathrm{H}$ NMR $\left(\mathrm{D}_{2} \mathrm{O}, 300 \mathrm{MHz}\right) \delta$ (ppm) $5.19(1 \mathrm{H}, H-1$, substituted at position 2$), 5.00(1 \mathrm{H}, H-1$, 
unsubstituted), 4.20-3.37 (6H + DS × 2H, H-2,3,4,5,6a,b + $\left.\mathrm{OCH}_{2}\right), 2.82\left(2 \mathrm{H}, \mathrm{CH}_{2} \mathrm{CN}\right)$; CED-3: ${ }^{1} \mathrm{H}$ NMR (DMSO- $d_{6}$, $400 \mathrm{MHz}) \delta(\mathrm{ppm}) 5.03(1 \mathrm{H}, H-1), 5.40-4.64 \mathrm{OH}-4, \mathrm{OH}-3$, $\mathrm{O} H-2$ overlapped by $H-1$ shifted due to substitution), 4.10-3.62 $\left(6 \mathrm{H}+\mathrm{DS} \times 2 \mathrm{H}, \mathrm{H}-2,3,4,5,6, \mathrm{ab}+\mathrm{OCH}_{2}\right), 2.76\left(2 \mathrm{H}, \mathrm{CH}_{2} \mathrm{CN}\right)$.

${ }^{1} \mathrm{H}$ NMR of CEP-1 and CEP-2: ${ }^{1} \mathrm{H}$ NMR $\left(\mathrm{D}_{2} \mathrm{O}, 300 \mathrm{MHz}\right) \delta$ (ppm) 5.77-4.86 (OH-2, OH-3, of glucosyl unit A, B and C + $H-1$, substituted and unsubstituted of glucosyl unit $\mathrm{A}, \mathrm{B}$ and $\mathrm{C})$, 4.21-3.36 (6H, H-2,3,4,5,6,a,b + $\left.\mathrm{OCH}_{2}\right), 2.80\left(2 \mathrm{H}, \mathrm{CH}_{2} \mathrm{CN}\right)$; CEP-3: ${ }^{1} \mathrm{H}$ NMR (DMSO- $\left.d_{6}, 400 \mathrm{MHz}\right) \delta$ (ppm) 5.95-4.75 $(\mathrm{OH}-2, \mathrm{OH}-3$, of glucosyl unit A, B and $\mathrm{C}+\mathrm{H}-1$, substituted and unsubstituted, glucosyl unit A,B and $\mathrm{C}), 4.11-3.20(6 \mathrm{H}$, $\left.\mathrm{H}-2,3,4,5,6, \mathrm{a}, \mathrm{b}+\mathrm{OCH}_{2}\right), 2.77\left(2 \mathrm{H}, \mathrm{CH}_{2} \mathrm{CN}\right)$.

\section{Monomer analysis of cyanoethylpolysaccha- rides}

The monomer composition of cyanoethyl derivatives was determined by GLC (twofold determination) after hydrolysis and trimethylsilylation according to [3]. The effective carbon response concept was applied for quantitative GLC-FID evaluation [37]. Peak areas were corrected by multiplication with the following factors: TMS O-CE/O-TMS-Glc: un- $\equiv 1.0000$, mono- 1.0694, di- 1.1491, and trisubstituted 1.2416; carboxyethyl-TMS-ester (from hydrolysis of the nitrile group): mono- 0.9250 , di- $0.9840\left(\mathrm{CH}_{2} \mathrm{CH}_{2} \mathrm{COOTMS} / \mathrm{CE}\right)$, $0.8605\left(2 \times \mathrm{CH}_{2} \mathrm{CH}_{2} \mathrm{COOTMS}\right)$, trisubstituted $1.0511(2 \times$ $\left.\mathrm{CH}_{2} \mathrm{CH}_{2} \mathrm{COOTMS} / \mathrm{CE}\right)$.

\section{Preparation of nanoscaled structures Iron nanoparticle dispersion}

A solution of a mixture of $\mathrm{Fe}(\mathrm{II})$ and $\mathrm{Fe}$ (III) chlorides in a molar ratio of 1.7:1.0 was prepared in distilled water. Aqueous ammonia solution $(25 \mathrm{~mL}, 25 \%)$ was added and the mixture was heated at $70{ }^{\circ} \mathrm{C}$ for $30 \mathrm{~min}$. After ultrasonic treatment the resulting particles were fixed with strong magnets, and the nonmagnetic products were removed by washing with distilled water three times and adjusted to $\mathrm{pH} 2.1$ with $\mathrm{HCl}[17,40,41]$.

\section{Polysaccharide nanoparticles}

Polysaccharide $(20 \mathrm{mg})$ was dissolved in $5 \mathrm{~mL}$ DMSO. Nanoparticles of cyanoethylglucans were prepared by a dialysis process against water [12]. For entrapping of iron oxide nanoparticles, various portions were mixed with the cyanoethylpolysaccharides before dialysis.

\section{Acknowledgements}

The authors are thankful to Dr. Ilka Grabs and Prof. Dr. Georg Garnweitner, Institute for Particle Technology, TU Braunschweig, for fruitful discussions and the opportunity of using their DLS instrument. Furthermore, the authors thank Prof. Dr.
Thomas Heinze, Friedrich-Schiller-Universität Jena, for the introduction to the preparation of ferromagnetic nanoparticels. Thanks also go to Mrs. Christiane Schmidt, Institute for Ecological Chemistry, TU Braunschweig, for performing ICP-OES measurements, and Dennis Rosebrock, Institute for Robotics and Process Control, TU Braunschweig for the image data processing program.

\section{References}

1. Volkert, B.; Wagenknecht, W.; Mai, M. Structure-Property Relationship of Cellulose Ethers - Influence of the Synthetic Pathway on Cyanoethylation. In Cellulose Solvents: For Analysis, Shaping and Chemical Modification; Liebert, T. F.; Heinze, T. J.; Edgar, K. J., Eds.; ACS Symposium Series, Vol. 1033; American Chemical Society: Washington DC, 2010; pp 319-341.

2. Verraest, D. L.; da Silva, L. P.; Peters, J. A.; van Bekkum, H. Starch/Staerke 1996, 48, 191-195. doi:10.1002/star.19960480509

3. Gonera, A.; Goclik, V.; Baum, M.; Mischnick, P. Carbohydr. Res. 2002, 337, 2263-2272. doi:10.1016/S0008-6215(02)00115-5

4. Onda, Y.; Muto, H.; Suzuki, H. Cyanoethylpullulan. U. S. Patent 4,322,524, March 30, 1982.

5. Gonera, A.; Mischnick, P.; Ukeda, H. Enzyme Microb. Technol. 2004, 34, 248-254. doi:10.1016/j.enzmictec.2003.10.008

6. Ademovic, Z.; Gonera, A.; Mischnick, P.; Klee, D. Biomacromolecules 2006, 7, 1429-1432. doi:10.1021/bm050591r

7. Verraest, D. L.; Peters, J. A.; Kuzee, H. C.; Raaijmakers, H. W. C.; van Bekkum, H. Carbohydr. Res. 1997, 302, 203-212. doi:10.1016/S0008-6215(97)00127-4

8. Verraest, D. L.; Zitha-Bovens, E.; Peters, J. A.; van Bekkum, H. Carbohydr. Res. 1998, 310, 109-115. doi:10.1016/S0008-6215(98)00174-8

9. Yoshida, H.; Takei, F.; Sawatari, N. Fujitsu Sci. Tech. J. 2002, 38, 39-45.

10. Taniguchi, M.; Kawai, T. Appl. Phys. Lett. 2004, 85, 3298-3300. doi:10.1063/1.1801167

11. Hornig, S.; Heinze, T. Carbohydr. Polym. 2007, 68, 280-286. doi:10.1016/j.carbpol.2006.12.007

12. Hornig, S.; Heinze, T. Biomacromolecules 2008, 9, 1487-1492. doi: $10.1021 / \mathrm{bm} 8000155$

13. Hornig, S.; Heinze, T.; Becer, C. R.; Schubert, U. S. J. Mater. Chem. 2009, 19, 3838-3840. doi:10.1039/b906556n

14. Liebert, T.; Hornig, S.; Hesse, S.; Heinze, T. J. Am. Chem. Soc. 2005, 127, 10484-10485. doi:10.1021/ja052594h

15. Tahir, M. N.; Bork, C.; Risberg, A.; Horst, J. C.; Komoß, C.; Vollmer, A.; Mischnick, P. Macromol. Chem. Phys. 2010, 211, 1648-1662. doi:10.1002/macp.200900700

16. Likhitkar, S.; Bajpai, A. K. Carbohydr. Polym. 2012, 87, 300-308. doi:10.1016/j.carbpol.2011.07.053

17. Wotschadlo, J.; Liebert, T.; Heinze, T.; Wagner, K.; Schnabelrauch, M.; Dutz, S.; Müller, R.; Steiniger, F.; Schwalbe, M.; Kroll, T. C.; Höffken, K.; Buske, N.; Clement, J. H. J. Magn. Magn. Mater. 2009, 321, 1469-1473. doi:10.1016/j.jmmm.2009.02.069

18. McCarthy, J. R.; Weissleder, R. Adv. Drug Delivery Rev. 2008, 60, 1241-1251. doi:10.1016/j.addr.2008.03.014

19. Kawaguchi, T.; Hanaichi, T.; Hasegawa, M.; Maruno, S. J. Mater. Sci.: Mater. Med. 2001, 12, 121-127. doi:10.1023/A:1008961709559 
20. Hornig, S.; Biskup, C.; Gräfe, A.; Wotschadlo, J.; Liebert, T.; Mohr, G. J.; Heinze, T. Soft Matter 2008, 4, 1169-1172. doi:10.1039/b800276b

21. Chatterjee, P. K.; Conrad, C. M. J. Polym. Sci., Part A-1 1966, 4, 233-243. doi:10.1002/pol.1966.150040115

22. Li, Q.; Wu, P.; Zhou, J.; Zhang, L. Cellulose 2011, 19, 161-169. doi:10.1007/s10570-011-9609-9

23. Mischnick, P.; Momcilovic, D. Chemical Structure Analysis of Starch and Cellulose Derivatives. In Advances in Carbohydrate Chemistry and Biochemistry; Horton, D., Ed.; Academic Press, 2010; Vol. 64, pp 117-210. doi:10.1016/S0065-2318(10)64004-8

24. Kawahara, K.; Ohta, K.; Miyamoto, H.; Nakamura, S. Carbohydr. Polym. 1984, 4, 335-356. doi:10.1016/0144-8617(84)90049-3

25. De Geest, B. G.; Van Camp, W.; Du Prez, F. E.; De Smedt, S. C.; Demeester, J.; Hennink, W. E. Chem. Commun. 2008, 190-192. doi:10.1039/b714199h

26. Kuroda, K.; Fujimoto, K.; Sunamoto, J.; Akiyoshi, K. Langmuir 2002, 18, 3780-3786. doi:10.1021/la011454s

27. Na, K.; Lee, E. S.; Bae, Y. H. J. Controlled Release 2003, 87, 3-13. doi:10.1016/S0168-3659(02)00345-0

28. Kimoto, T.; Shibuya, T.; Shiobara, S. Food Chem. Toxicol. 1997, 35, 323-329. doi:10.1016/S0278-6915(97)00001-X

29. European Food Safety Authority. EFSA J. 2004, 89, 1-35.

30. Leathers, T. D. Appl. Microbiol. Biotechnol. 2003, 62, 468-473. doi:10.1007/s00253-003-1386-4

31. Larm, O.; Lindberg, B.; Svensson, S. Carbohydr. Res. 1971, 20 , 39-48. doi:10.1016/S0008-6215(00)84947-2

32. Rolland-Sabaté, A.; Mendez-Montealvo, M. G.; Colonna, P.; Planchot, V. Biomacromolecules 2008, 9, 1719-1730. doi:10.1021/bm7013119

33. Fahner, E. M.; Großmann, G. H.; Ebert, K. H. Makromol. Chem. 1984, 185, 2205-2212.

34. Heinze, T.; Liebert, T.; Heublein, B.; Hornig, S. In Functional Polymers based on Dextran; Klemm, D., Ed.; Advances in Polymer Science, Vol. 205; Springer: Berlin/Heidelberg, 2006; pp 199-291.

35. van Dijk, M.; Rijkers, D. T. S.; Liskamp, R. M. J.; van Nostrum, C. F.; Hennink, W. E. Bioconjugate Chem. 2009, 20, 2001-2016. doi:10.1021/bc900087a

36. Bruneel, D.; Schacht, E.; De Bruyn, A. J. Carbohydr. Chem. 1993, 12, 769-778. doi:10.1080/07328309308019006

37. Sweet, D. P.; Shapiro, R. H.; Albersheim, P. Carbohydr. Res. 1975, 40, 217-225. doi:10.1016/S0008-6215(00)82604-X

38. Vollmer, A.; Voiges, K.; Bork, C.; Fiege, K.; Cuber, K.; Mischnick, P. Anal. Bioanal. Chem. 2009, 395, 1749-1768. doi:10.1007/s00216-009-3013-4

39. Liebert, T.; Hornig, S.; Hesse, S.; Heinze, T. Macromol. Symp. 2005, 223, 253-266. doi:10.1002/masy.200550518

40. Khalafalla, S.; Reimers, G. IEEE Trans. Magn. 1980, 16, 178-183. doi:10.1109/TMAG.1980.1060578

41. Massart, R. IEEE Trans. Magn. 1981, 17, 1247-1248. doi:10.1109/TMAG.1981.1061188

42. Hong, X.; Guo, W.; Yuan, H.; Li, J.; Liu, Y.; Ma, L.; Bai, Y.; Li, T. J. Magn. Magn. Mater. 2004, 269, 95-100. doi:10.1016/S0304-8853(03)00566-3
43. Reimer, L.; Zepke, U.; Moesch, J.; Schulze-Hillert, S.; Ross-Messemer, M.; Probst, W.; Weimer, E. EELSpectroscopy. A Reference Handbook of Standard Data for Interpretation of Electron Energy Loss Spectra and for Generation of Electron Spectroscopic Images; Institute of Physics, University of Münster: Münster, Germany, and Carl Zeiss, Electon Optics Division: Oberkochen, Germany, 1992.

44. Egerton, R. F. Electron Energy-Loss Spectroscopy in the Electron Microscope; Plenum Press: New York, London, 1996.

45. van Aken, P. A.; Liebscher, B.; Styrsa, V. J. Phys. Chem. Miner. 1998, 25, 323-327. doi:10.1007/s002690050122

46. Cressey, G.; Henderson, C. M. B.; Laan, G. Phys. Chem. Miner. 1993, 20, 111-119. doi:10.1007/BF00207204

47. Garvie, L. A. J.; Craven, A. J.; Brydson, R. Am. Mineral. 1994, 79, 411-425.

48. Hedrich, S.; Lünsdorf, H.; Kleeberg, R.; Heide, G.; Seifert, J.; Schlömann, M. Environ. Sci. Technol. 2011, 45, 7685-7692. doi:10.1021/es201564g

\section{License and Terms}

This is an Open Access article under the terms of the Creative Commons Attribution License

(http://creativecommons.org/licenses/by/2.0), which permits unrestricted use, distribution, and reproduction in any medium, provided the original work is properly cited.

The license is subject to the Beilstein Journal of Organic Chemistry terms and conditions:

(http://www.beilstein-journals.org/bjoc)

The definitive version of this article is the electronic one which can be found at: doi: $10.3762 /$ bjoc. 8.63 